NBER WORKING PAPER SERIES

\title{
INSURANCE AND OPPORTUNITIES: A WELFARE ANALYSIS OF LABOR MARKET RISK
}

\author{
Jonathan Heathcote \\ Kjetil Storesletten \\ Giovanni L. Violante \\ Working Paper 13673 \\ http://www.nber.org/papers/w13673 \\ NATIONAL BUREAU OF ECONOMIC RESEARCH \\ 1050 Massachusetts Avenue \\ Cambridge, MA 02138 \\ December 2007
}

We would like to thank, without implicating, Randy Wright. Several ideas in this paper originated from a conversation we had with him. We also thank Marco Bassetto, Jeremy Greenwood, Guido Lorenzoni, Victor Rios-Rull, one anonymous referee, and participants to many seminars and conferences for comments. Heathcote and Violante thank the Economics Program of the National Science Foundation (grant SES 0418029) for financial support. The views expressed herein are those of the author(s) and do not necessarily reflect the views of the National Bureau of Economic Research.

(C) 2007 by Jonathan Heathcote, Kjetil Storesletten, and Giovanni L. Violante. All rights reserved. Short sections of text, not to exceed two paragraphs, may be quoted without explicit permission provided that full credit, including (C) notice, is given to the source. 
Insurance and Opportunities: A Welfare Analysis of Labor Market Risk

Jonathan Heathcote, Kjetil Storesletten, and Giovanni L. Violante

NBER Working Paper No. 13673

December 2007

JEL No. E21,J22,J31

\begin{abstract}
$\underline{\text { ABSTRACT }}$
Using a model with constant relative risk-aversion preferences, endogenous labor supply and partial insurance against idiosyncratic wage risk, we provide an analytical characterization of three welfare effects: (a) the welfare effect of a rise in wage dispersion, (b) the welfare gain from completing markets, and (c) the welfare effect from eliminating risk. Our analysis reveals an important trade-off for these welfare calculations. On the one hand, higher wage uncertainty increases the cost associated with missing insurance markets. On the other hand, greater wage dispersion presents opportunities to raise aggregate productivity by concentrating market work among more productive workers. Our welfare effects can be expressed in terms of the underlying parameters defining preferences and wage risk, or alternatively in terms of changes in observable second moments of the joint distribution over individual wages, consumption and hours.
\end{abstract}

Jonathan Heathcote

Dept. of Economics

Georgetown University

ICC Bldg. 5th Floor

Washington, DC 20057

jhh9@georgetown.edu

Kjetil Storesletten

Department of Economics

University of Oslo

Box 1095 Blindern

N-0317 Oslo

Norway

kjetil.storesletten@econ.uio.no
Giovanni L. Violante

Department of Economics

New York University

19 W. 4th Street

New York, NY 10012-1119

and NBER

glv2@nyu.edu 


\section{Introduction}

Cross-sectional wage dispersion and individual wage volatility over the life-cycle are large. For example, the variance of the growth rate of individual wages in the United States in the cross-section is over 100 times larger than the variance of the growth rate of average wages over time. ${ }^{1}$ Moreover, there has been a sharp increase in wage dispersion in the United States over the past thirty years. ${ }^{2}$ An important task for macroeconomists is to study the welfare consequences of this phenomenon.

In this paper, we develop a tractable class of dynamic heterogeneous-agent economies with partial insurance against idiosyncratic labor productivity (wage) risk and with endogenous labor supply. The process for idiosyncratic wages has two orthogonal components: an uninsurable piece, and a component that may be fully insured. This modelling strategy for market incompleteness allows us to solve for the equilibrium allocations in closed form, which in turn leads to a transparent welfare analysis.

Several authors have examined the welfare consequences of changes in earnings or income risk. ${ }^{3}$ We focus instead on wage risk and endogenize labor supply because the ability to adjust hours can mitigate the welfare cost of rising wage inequality via two alternative channels. First, agents may vary hours worked inversely with fluctuations in individual wages, thereby reducing fluctuations in earnings. Alternatively, agents may choose to work more hours in periods when individual wages are high, thereby increasing average earnings per hour. A negative wage-hour correlation is more likely to be observed if agents cannot smooth income by other means, such as by purchasing explicit insurance against wage risk. Conversely the wage-hour correlation will be positive if wage inequality can be insured directly within financial markets. Thus the model highlights an interesting interaction between the asset market structure and the role of endogenous labor supply in absorbing idiosyncratic wage shocks. ${ }^{4}$

\footnotetext{
${ }^{1}$ This number is calculated from the PSID, 1967-1996. The variance of the mean wage growth over the period is 0.0012 and the cross-sectional variance of individual wage growth, averaged over the period, is 0.161. See Section 7 for details on the sample selection.

${ }^{2}$ For surveys on the causes of the changes in inequality, see Katz and Autor (1999), Acemoglu (2002), Aghion (2002), and Hornstein, Krusell and Violante (2005).

${ }^{3}$ See e.g. Attanasio and Davis (1996); Blundell and Preston (1998); Krueger and Perri (2006); and Krebs, Krishna and Maloney (2005).

${ }^{4}$ Low (2005) explores the implications of this interaction for the life-cycle profiles of consumption, hours and asset holdings.
} 
We consider two standard classes of time-additive preferences with constant relative risk aversion; one in which agents have CRRA preferences over a Cobb-Douglas composite of consumption and leisure, and one in which preferences are additively separable between consumption and hours worked. For each preference specification we derive intuitive analytic solutions for equilibrium allocations and expected lifetime utility as functions only of preference parameters and of the variances of the insurable and uninsurable components in individual labor productivity. These transparent expressions enable us to answer three distinct questions related to welfare and inequality. ${ }^{5}$

First, what are the welfare costs of rising wage dispersion, holding constant the asset market structure? Second, what are the welfare costs of market incompleteness, defined as the difference between expected lifetime utility in the baseline incomplete-markets economy versus a complete-markets economy, holding constant the wage-generating process? Third, what are the welfare effects from eliminating individual wage risk? This last welfare calculation is the cross-sectional equivalent of the calculation underlying the vast literature on the welfare costs of business cycles fluctuations (for a survey, see Lucas, 2003). Note that these three inquiries reflect changes in different primitives of the model: technology in the first (e.g., skill-biased technical change), markets in the second (e.g., the emergence of new financial instruments), and policies in the third (e.g., redistributive taxation schemes that align ex-post wages across all workers).

When labor supply is flexible, increased wage inequality impacts not only consumption inequality, but also leisure inequality and the average values for consumption and leisure. More precisely, welfare effects are driven by two offsetting forces: an increase in idiosyncratic wage risk increases the need for insurance, but also presents opportunities to increase the level of aggregate productivity, measured as output per hour worked, by concentrating work effort among more productive workers. To clarify the trade-off between risk and opportunities, we decompose the overall welfare effects into the relative contributions of changes in aggregate consumption and leisure on the one hand, and changes in the cross-sectional dispersion of these variables on the other (see also Benabou, 2002; and Flodén, 2001).

A related point is that there is an important difference between insuring risk and elimi-

\footnotetext{
${ }^{5}$ It should be clarified that we study inequality in individual labor productivities within a competitive labor market. Thus we do not analyze "frictional inequality" - pure wage dispersion arising between ex ante identical workers because of search frictions (e.g., Mortensen, 2003).
} 
nating risk when labor supply is flexible. In fact, eliminating risk will always lead to smaller welfare gains than insuring risk, because removing risk also takes away opportunities to increase average labor productivity.

The first set of analytical welfare expressions we report incorporate structural model parameters defining preferences and the insurability of wage risk. A key result of the paper is that welfare effects can alternatively be expressed as simple functions of various moments of the cross-sectional joint distribution over wages, hours and consumption. For example, in the separable-preferences case, the welfare effect associated with a change in the wage process can be expressed as the sum of the changes in (i) the covariance between log-wages and log-hours, (ii) the variance of log-consumption weighted by the coefficient of relative risk-aversion, and (iii) the variance of log-hours weighted by the inverse of the labor supply elasticity.

This representation of welfare effects has two advantages relative to our first structuralmodel-based set of welfare expressions. First, it is more general, since it does not depend on the particular market structure assumed. In particular, the expression applies to any economy in which the standard intratemporal consumption-leisure first order condition condition is satisfied, and in which equilibrium allocations and wages are jointly log-normally distributed. The second advantage is that we do not have to take a stand on the fraction of wage risk that is insurable. Thus we can estimate welfare effects simply by computing the relevant moments in repeated cross-sections and assigning values to preference parameters. However, a drawback with the cross-sectional-moment-based representation is that it requires high-quality data on consumption and hours, while the first approach only requires panel data on wages. We therefore view the two alternative approaches as complementary. In the rest of the paper, we refer to the first set of welfare expressions as "model-based" and to the second as "observables-based".

In the quantitative part of the paper we compute the answers to our three welfare questions by calibrating the model to the U.S. economy. With Cobb-Douglas preferences and a coefficient of relative risk aversion equal to two, the welfare cost of the rise in labor market risk in the U.S. over the past 30 years in the incomplete-markets economy is $2.5 \%$ of lifetime consumption. This number is the combination of a welfare loss of $7.5 \%$ due to larger uninsurable fluctuations in individual consumption and hours, and a welfare gain of $5 \%$ from an increase in aggregate labor productivity. 
For the same preferences, households would be willing, ex-ante, to give up almost $40 \%$ of their expected lifetime consumption in exchange for access to complete markets. One might suspect that this welfare gain stems from reducing inequality in the cross-sectional distributions for consumption and leisure. Instead, we find that two thirds of the welfare gains from completing markets take the form of higher average productivity. Thus our analysis highlights an important cost of missing markets that has been largely overlooked to date, namely the loss in aggregate labor productivity that arises when low productivity agents work too much (because lack of insurance makes them inefficiently poor) while high productivity agents work too little (because lack of insurance makes them inefficiently rich).

Finally, we find that eliminating all individual wage risk through distortionary taxation delivers a welfare gain which is only about half the size of the gain from completing markets, but at least two orders of magnitude larger than Lucas' estimates of the potential welfare gains from stabilizing business cycles (0.008-0.1 percent of average consumption).

The main contribution of our paper is to clarify what drives the welfare effects of changes in the wage process, emphasizing the role of labor supply. In addition, our simple framework can also shed light on the quantitative findings of richer incomplete-markets models with more complex interaction between wages and the wealth distribution. In particular, when properly calibrated, our model delivers quantitatively similar results to Krueger and Perri (2003), and Pijoan-Mas (2005). The advantage of our approach is that welfare effects can be solved for in closed form (rather than via numerical solution and simulation), and consequently the roles of preference parameters, wage risk parameters and market structure are all transparent.

The rest of the paper is organized as follows. Section 2 describes the model economies, and Section 3 defines our three welfare measures. Sections 4 and 5 characterize equilibrium allocations and the analytical model-based welfare expressions that obtain under the two alternative preference specifications we consider. Section 6 derives the alternative observablesbased welfare representation. Section 7 describes the calibration to the U.S., and reports our quantitative results. Section 8 concludes the paper.

\section{The Economy}

Demographics and preferences: The economy is populated by a unit mass of infinitelylived agents. Each agent has the same time-separable utility function over streams of con- 
sumption $\left\{c_{t}\right\}_{t=0}^{\infty}$ and hours worked $\left\{h_{t}\right\}_{t=0}^{\infty}$,

$$
\mathcal{W}=(1-\beta) \mathbb{E}_{0} \sum_{t=0}^{\infty} \beta^{t} u\left(c_{t}, h_{t}\right)
$$

where $\beta \in(0,1)$ is the agents' discount factor. We will consider two alternative specifications for the period utility function. In the first, consumption and leisure $\left(1-h_{t}\right)$ enter in a CobbDouglas fashion. In the second, period utility is separable between consumption and hours worked.

Production and individual labor productivity: The aggregate production function exhibits constant returns to scale with labor as the only input. Output cannot be stored. The labor market and the goods market are perfectly competitive, so individual wages equal individual productivity. Since we do not focus on growth or aggregate short-term fluctuations, we normalize the hourly rental rate per efficiency unit of labor to unity.

Individuals' wage rates vary stochastically over time, and are independently and identically distributed across the agents in the economy. We assume that an individual's log wage at a point in time has two orthogonal components: a fixed effect $\alpha \in A \subseteq \mathfrak{R}$, and a transitory iid shock $\varepsilon_{t} \in E \subseteq \Re$ :

$$
\log w_{t}=\alpha+\varepsilon_{t}
$$

The fixed effect $\alpha$ is drawn in an initial period prior to the start of period 0 . Then for every $t \geq 0$, each agent draws a value for $\varepsilon_{t} \cdot{ }^{6}$ Let $\Phi_{v}$ denote the Normal cumulative distribution function with mean $-\frac{v}{2}$ and variance $v$. Then, $\varepsilon_{t} \sim \Phi_{v_{\varepsilon}}$ and $\alpha \sim \Phi_{v_{\alpha}}$. As a result, $\log w \sim \Phi_{v}$, where $v=v_{\varepsilon}+v_{\alpha}$, which implies that the population mean wage (in levels) is equal to one. The fact that the mean wage is invariant to dispersion will turn out to be convenient when we study comparative statics with respect to the variances $v_{\varepsilon}$ and $v_{\alpha}$.

Market structure: Households have access to perfect insurance against the transitory $\varepsilon$-shocks and no insurance against the permanent $\alpha$-shocks. Since $\alpha$ is not insured, the equilibrium of this economy will only offer partial insurance. The extent to which insurance

\footnotetext{
${ }^{6}$ These assumptions on the statistical representation of the shocks are made mainly for ease of exposition. In Heathcote, Storesletten and Violante (2007b) we demonstrate that the analysis can be extended to allow for a richer specification of the wage process, while still retaining analytical tractability. The process for $\alpha$ (the uninsurable component) can incorporate permanent shocks, and the process for $\varepsilon$ (the insurable component) can virtually follow any ARIMA process.
} 
is incomplete depends on the size of $v_{\alpha}$ relative to $v_{\varepsilon}$. We define competitive equilibria sequentially: all assets traded are one-period-ahead Arrow securities in zero net supply.

Budget constraints: The period- $t$ budget constraint is given by

$$
c_{t}+\int_{E} p_{t}\left(\varepsilon^{\prime}\right) b_{t}\left(\varepsilon^{\prime}\right) d \varepsilon^{\prime}=b_{t-1}+w_{t} h_{t} \quad t \geq 0
$$

where $b_{t-1}$ is the realized gross return on assets purchased in $t-1$, and $p_{t}\left(\varepsilon^{\prime}\right)$ and $b_{t}\left(\varepsilon^{\prime}\right)$ are functions defining respectively the price and quantity purchased of securities that pay one unit of output in period $t+1$ contingent on the realization of $\varepsilon_{t+1}$. An arbitrarily loose constraint on borrowing rules out Ponzi schemes.

In period $t=-1$, the timing is as follows. First $\alpha$ is drawn. Then financial markets open offering state-contingent claims conditional on the realization of $\varepsilon_{0}$. Agents are born with zero financial wealth, so the initial portfolio purchased must satisfy the budget constraint

$$
\int_{E} p_{t}\left(\varepsilon^{\prime}\right) b_{t}\left(\varepsilon^{\prime}\right) d \varepsilon^{\prime}=0 \quad t=-1
$$

Discussion: Our model imposes exogenously a specific market structure leading to partial insurance. In this respect, it belongs to the set of models in which markets are exogenously incomplete, a set which also includes "Bewley models" in which asset trade is limited to a non-contingent bond. Our approach to modelling partial insurance is designed to capture, in a tractable way, the fact that actual economies allow some degree of risk sharing through a variety of channels, but not perfect risk-sharing. ${ }^{7}$ We partition risks into two categories: the first set of risks are assumed transitory in nature and fully insurable, while the second are permanent and fully uninsurable. There are at least two ways to motivate these assumptions.

First, one natural interpretation of our framework is as an approximation to models in the Bewley (1986) tradition in which a single risk-free asset is traded. Even though these models do not have explicit insurance markets, allocations in the two environments are very similar

\footnotetext{
${ }^{7}$ Cochrane (1991) finds evidence of full insurance against short-lived transitory income shocks (e.g. short spell of illness, absence from work due to strikes). Altonji, Hayashi and Kotlikoff (1992) argue that some income shocks are fully absorbed within the family. Guiso, Pistaferri, and Schivardi (2005) show that a sizeable fraction of firm-level productivity shocks are insured by the firm and do not transmit to workers. Livshits et al. (2006) demonstrate that bankruptcy laws act as effective insurance against some states with low income realizations.
} 
because borrowing and saving through a risk-free asset allows for near-perfect smoothing of transitory shocks, but provides no insurance against permanent productivity differences. ${ }^{8}$ However, while Bewley models require numerical solution, equilibrium allocations in our economies can be characterized analytically, as shown below. In Section 7 we revisit the comparison between these two models.

Second, one could interpret the model literally as capturing that there exists explicit insurance against some risks (such as short spells of unemployment or illness) but not against others (such as being endowed with low ability or being born to poor or uneducated parents). In environments where market incompleteness emerges endogenously as a result of informational or enforcement frictions, it is typically relatively easy to provide insurance against transitory risks, and relatively hard to provide insurance against permanent risks. This suggests a further rationale for our assumed mapping between the persistence of shocks and their insurability. ${ }^{9}$

Solving for the equilibrium: It is instructive to sketch our approach for finding the competitive equilibrium allocations (see Appendix A for full details). We start by guessing that because the distributions for $\alpha$ and $\varepsilon$ are independent, agents can perfectly diversify shocks to $\varepsilon$ by trading Arrow securities only with other agents sharing their particular realization for $\alpha$. In other words, we guess that the economy is equivalent to a world in which agents are distributed across segregated " $\alpha$-islands", where each island is a closed economy with complete insurance against the $\varepsilon$ shocks. We can then solve for allocations at the island level using a static planner's problem with equal weights (equal since all members of an island share the same uninsurable component $\alpha$ and have zero initial financial wealth). The planner chooses how to allocate labor effort and consumption among all agents on the island, subject to a resource constraint that equates aggregate island consumption to aggregate island production. Given these allocations, we compute the implied prices of Arrow securities in the corresponding within-island competitive equilibria, and verify that these prices do not depend on $\alpha$. This confirms the initial guess of no trade between $\alpha$-islands. ${ }^{10}$

\footnotetext{
${ }^{8}$ See Deaton (1991) and Carroll (1997) for discussions on the role of precautionary saving in smoothing income shocks which are not too persistent.

${ }^{9}$ See, for example, Huggett and Parra (2006) and Krueger and Perri (2006) for discussions of the link between persistence of shocks and ability to provide insurance in economies with, respectively, private information and limited commitment frictions.

${ }^{10}$ In Heathcote et al. (2007b) we show that this approach for solving for the equilibrium allocations remains valid even when agents face permanent stochastic innovations to $\alpha$.
} 
A very convenient property of equilibrium allocations that follows intuitively from the solution method is that the pair $(\alpha, \varepsilon)$ constitutes a sufficient statistic for equilibrium individual consumption, hours worked, and start of period asset holdings. It is not necessary to include individual financial wealth as a separate state variable when characterizing consumption and hours worked because the distribution of individual wealth naturally does not appear in the planner's problem that is used to solve for within-island allocations. This feature of the economy simplifies the solution considerably, since instead of keeping track of the endogenous evolution of individual wealth, we need only worry about the exogenous evolution of individual labor productivity. By contrast, in the typical Bewley model, no shocks can be perfectly insured, and the welfare theorems do not apply. Thus the competitive equilibrium must be tackled directly, which means including individual wealth as an endogenous state variable.

We denote the time-invariant functions defining equilibrium individual wages, consumption, hours and start-of-period asset holdings $w(\alpha, \varepsilon), c(\alpha, \varepsilon), h(\alpha, \varepsilon)$ and $b(\alpha, \varepsilon)$ respectively.

\section{Three welfare questions}

We compare and rank allocations using the following utilitarian social welfare function:

$$
\mathcal{W}=(1-\beta) \mathbb{E}_{0} \sum_{t=0}^{\infty} \beta^{t} u\left(c_{t}, h_{t}\right)=\int_{A} \int_{E} u(c(\alpha, \varepsilon), h(\alpha, \varepsilon)) d \Phi_{v_{\varepsilon}}(\varepsilon) d \Phi_{v_{\alpha}}(\alpha)
$$

This expression for welfare has two interpretations. First, it is the value for a utilitarian planner who weights all agents equally. Second, it is the expected lifetime utility for an agent at time $t=0$ "under the veil of ignorance", i.e., before uncertainty is realized.

We assess the welfare costs associated with labor market uncertainty from three related perspectives. First, given the insurance market structure, what is the welfare effect of a rise in labor market risk? Second, for a given level of risk, what are the welfare gains from completing markets? Third, what is the welfare gain from eliminating all labor market risk?

Welfare effect from rising labor market risk: Suppose the variances of permanent and transitory shocks rise from $v_{\alpha}$ and $v_{\varepsilon}$ to $\widehat{v}_{\alpha}$ and $\widehat{v}_{\varepsilon}$, respectively. Let $\Delta v_{\alpha}=\widehat{v}_{\alpha}-v_{\alpha}$ and $\Delta v_{\varepsilon}=\widehat{v}_{\varepsilon}-v_{\varepsilon}$. Let $\omega$ denote the associated welfare gain, expressed in units of the "equivalent 
compensating variation" in lifetime consumption under the baseline wage variance:

$$
\int_{A} \int_{E} u((1+\omega) c(\alpha, \varepsilon), h(\alpha, \varepsilon)) d \Phi_{v_{\varepsilon}}(\varepsilon) d \Phi_{v_{\alpha}}(\alpha)=\iint_{A} u(\widehat{c}(\alpha, \varepsilon), \widehat{h}(\alpha, \varepsilon)) d \Phi_{\widehat{v}_{\varepsilon}}(\varepsilon) d \Phi_{\widehat{v}_{\alpha}}(\alpha) .
$$

where $\widehat{c}(\alpha, \varepsilon)$ and $\widehat{h}(\alpha, \varepsilon)$ denote equilibrium choices in the economy with $\widehat{v}_{\alpha}$ and $\widehat{v}_{\varepsilon}$.

A theme of our paper is that increases in wage dispersion can impact aggregate productivity (by changing the covariance between hours worked and individual productivity) in addition to affecting the amount of risk that agents face. We are therefore interested in decomposing the overall welfare effect $\omega$ into two pieces - a level effect and a volatility effect. The level effect captures the welfare effect associated with changes in the size of the aggregate pie. The volatility effect captures the welfare effect associated with changes in how evenly the pie is distributed.

Formally, our strategy for identifying these two components closely follows that outlined by Flodén (2001), who in turn builds on earlier work by Benabou (2002). Let capital letters denote population averages. We define the level effect associated with an increase in wage dispersion (in units of consumption) as the value for $\omega^{\text {lev }}$ that solves:

$$
u\left(\left(1+\omega^{l e v}\right) C, H\right)=u(\widehat{C}, \widehat{H}) .
$$

Next, for an agent behind the veil of ignorance, define the cost of uncertainty (in terms of consumption) as the value for $p$ that solves

$$
u((1-p) C, H)=\iint_{A} u(c(\alpha, \varepsilon), h(\alpha, \varepsilon)) d \Phi_{v_{\varepsilon}}(\varepsilon) d \Phi_{v_{\alpha}}(\alpha)
$$

Note that the cost of uncertainty is a measure of the utility difference between drawing a lottery over $c(\alpha, \varepsilon)$ and $h(\alpha, \varepsilon)$ versus receiving the expected values for consumption and leisure associated with this lottery. Analogously, we can define the cost of uncertainty associated with the higher variances $\widehat{v}_{\alpha}$ and $\widehat{v}_{\varepsilon}$, which we denote $\widehat{p}$.

We then define the volatility effect $\omega^{\text {vol }}$ of an increase in wage dispersion as

$$
\left(1+\omega^{v o l}\right)(1-p)=1-\widehat{p} .
$$

Thus the volatility effect is the percentage change in the cost of uncertainty associated with the increase in wage dispersion. 
For both types of preferences, we will establish that the two components approximately sum to the total welfare effect, i.e., $\omega \simeq \omega^{l e v}+\omega^{v o l}$.

Welfare gains from completing markets: We measure the welfare gain associated with completing insurance markets, for given levels of permanent and transitory risk $v_{\alpha}$ and $v_{\varepsilon}$, as the percentage increase in consumption in the partial-insurance economy required to achieve the same welfare as in the economy with complete markets. In particular, we define the welfare gain as the value for $\chi$ that solves

$$
\int_{A} \int_{E} u((1+\chi) c(\alpha, \varepsilon), h(\alpha, \varepsilon)) d \Phi_{v_{\varepsilon}}(\varepsilon) d \Phi_{v_{\alpha}}(\alpha)=\iint_{A} u(c(0, \alpha+\varepsilon), h(0, \alpha+\varepsilon)) d \Phi_{v_{\varepsilon}}(\varepsilon) d \Phi_{v_{\alpha}}(\alpha),
$$

where the expression on the right-hand side reflects welfare when markets are complete and fluctuations in both $\alpha$ and $\varepsilon$ are insurable.

Completing markets amounts to reducing the variance of uninsurable risk, and simultaneously increasing the variance of insurable risk by the same amount $v_{\alpha}$. Thus the welfare effect can be read directly from the expression for $\omega$ in (4) by setting $\hat{v}_{\varepsilon}=v_{\varepsilon}+v_{\alpha}$ and $\hat{v}_{\alpha}=0$.

Welfare effect of eliminating risk: In computing the welfare cost of business cycles, Lucas (1987) compared welfare associated with the actual U.S. time series for aggregate consumption to welfare associated with the trend for the actual path. ${ }^{11}$ Thus he calculated the hypothetical welfare gain from eliminating aggregate fluctuations. We calculate the welfare gains from eliminating idiosyncratic risk by making the same actual to trend comparison as Lucas, but at the individual rather than the aggregate level. Thus we set every individual's wage at every date equal to its unconditional expected value.

For Lucas, eliminating aggregate fluctuations was a hypothetical thought experiment. One could view our experiment in a similar light, but in the context of our model this outcome can in fact be achieved via an appropriate policy of full wage compression. In particular, wage risk can be eliminated by a system of distortionary wage taxes and subsidies that guarantees each worker an after-tax hourly wage rate equal to average labor productivity, which in turn equals one. Thus, the tax (subsidy) rate paid by a worker with current pre-tax

\footnotetext{
${ }^{11}$ More recently, Storesletten et. al. (2001), Krusell and Smith (1999), and Krebs (2003) have made similar calculations in models with heterogeneous agents. See Lucas (2003) for a critical survey.
} 
wage $w$ is given by $\tau(w)=1-1 / w^{12}$

In the context of our model, eliminating wage risk amounts to reducing to zero the variances of both components of the wage process. Thus the welfare calculation can be read directly from the expression for $\omega$ in (4) by setting $\hat{v}_{\varepsilon}=0$ and $\hat{v}_{\alpha}=0$.

Finally, note that the solutions for $\omega, \chi$ and $\kappa$ represent welfare comparisons across two steady states characterized by different variances for wages. However, this does not imply that our welfare expressions ignore transitional dynamics. Rather the transition to a new steady state in response to a change in the wage process is immediate in our environment. ${ }^{13}$

\section{Cobb-Douglas preferences}

First, we consider preferences that are Cobb-Douglas between consumption and leisure, i.e.,

$$
u(c, h)=\frac{\left(c^{\eta}(1-h)^{1-\eta}\right)^{1-\theta}}{1-\theta} .
$$

where $\eta \in(0,1)$ determines the relative taste for consumption versus leisure. Cobb-Douglas preferences are widely used in the macro literature, since they are consistent with balanced growth, irrespective of the choice for $\theta$. In labor economics, this specification is often advocated because there is some empirical evidence of non-separability between consumption and leisure (Heckman, 1974; Browning and Meghir, 1991).

The parameter $\eta$ is generally pinned down by the share of disposable time agents devote to market work, implying that the single parameter $\theta$ governs both the intertemporal elasticity of substitution for consumption and the corresponding elasticity for hours worked. In particular, the intertemporal elasticity of substitution for consumption is given by $1 / \theta$.

\footnotetext{
${ }^{12}$ To verify that this system of wage taxes and subsidies is feasible we need to check that it is revenue neutral. Since every agent faces the same after-tax wage, each agent works the same number of hours per period and enjoys the same level of consumption. Per-capita consumption will equal per-capita after-tax income, which in turn is equal to (constant) hours times the after-tax wage, which is equal to one given the tax function $\tau(w)$. Since average labor productivity is also equal to one, output per-capita will equal consumption per-capita. It follows immediately that the tax-subsidy scheme is revenue-neutral.

${ }^{13}$ More precisely, the transition due to an unforeseen one-off change in the variances of either or both components of the wage process is immediate in the sense that our expected welfare measure (3) takes the same value in the period the wage process changes as in all subsequent periods. The key assumption underlying this result is that assets are in zero net supply.
} 
The coefficient of relative risk aversion is

$$
\bar{\gamma} \equiv \gamma(\theta, \eta) \equiv-\frac{c u_{c c}}{u_{c}}=1-\eta+\eta \theta
$$

The Frisch elasticity of labor supply depends on hours worked, and is given by $\phi(\theta, \eta, h)=$ $\lambda(1-h) / h$, where $\lambda \equiv(1-\eta+\eta \theta) / \theta$ defines the Frisch elasticity for leisure. ${ }^{14}$ It is useful to define a "non-stochastic Frisch" elasticity of labor supply corresponding to a non-stochastic version of the model, in which case $h=H=\eta$, where $H$ denotes average hours worked:

$$
\left.\bar{\phi} \equiv \phi(\theta, \eta, H) \equiv \frac{u_{h}}{u_{h h} h-\frac{u_{c h}^{2} h}{u_{c c}}}\right|_{h=H}=\frac{\lambda(1-\eta)}{\eta} .
$$

\subsection{Equilibrium allocations with Cobb-Douglas preferences}

The equilibrium consumption and leisure allocations in our partial-insurance economy are:

$$
\begin{aligned}
\log c(\alpha, \varepsilon) & =\log (\eta)+\alpha+(1-\lambda) \varepsilon+\lambda(1-\lambda) \frac{v_{\varepsilon}}{2} \\
\log (1-h(\alpha, \varepsilon)) & =\log (1-\eta)-\lambda \varepsilon+\lambda(1-\lambda) \frac{v_{\varepsilon}}{2} .
\end{aligned}
$$

The insurable transitory shock $\varepsilon$ reduces leisure proportionately to the Frisch elasticity for leisure $\lambda$. Moreover, leisure is independent of the permanent uninsurable component $\alpha$ since the income and substitution effects associated with an uninsurable change in the wage exactly offset with Cobb-Douglas utility.

Because $\alpha$ has no impact on hours worked, consumption is directly proportional to $\alpha$. Given non-separability between consumption and leisure, current consumption depends on the insurable shock $\varepsilon$ as long as $\lambda \neq 1$. For $\lambda<1$ (which is equivalent to $\theta>1$ ), consumption and leisure are substitutes, in the sense that the marginal utility of consumption is decreasing in leisure. In this case, in order to equate the marginal utility of consumption inter-temporally, individuals who draw a high value for $\varepsilon$ and who therefore enjoy relatively little leisure must be compensated with relatively high consumption. When $\theta=1$ (in which case $u(c, h)=\eta \log c+(1-\eta) \log (1-h))$, consumption is constant and equal to $\eta \exp (\alpha)$.

Note that individual consumption and leisure also depend on the variance of the insurable component of the log wage, $v_{\varepsilon}$. For $\lambda \in(0,1)$, both consumption and leisure are increasing

\footnotetext{
${ }^{14}$ The Frisch elasticity of labor supply (leisure) measures the elasticity of hours worked (leisure) to changes in wages, keeping the marginal utility of consumption constant.
} 
in insurable wage dispersion. We will return to this point when examining the welfare effects of a rise in wage dispersion.

Appendix A contains the derivations of the above expressions for $c(\alpha, \varepsilon)$ and $h(\alpha, \varepsilon)$. We also show that the cost of an individual's portfolio of Arrow securities is zero. Hence the budget constraint (2) implies that for each possible realization $\varepsilon^{\prime}$, the payoff from the corresponding Arrow security can alternatively and intuitively be expressed as the equilibrium value for current consumption net of current labor income, or

$$
b\left(\varepsilon^{\prime} ;(\alpha, \varepsilon)\right)=c\left(\alpha, \varepsilon^{\prime}\right)-w\left(\alpha, \varepsilon^{\prime}\right) h\left(\alpha, \varepsilon^{\prime}\right)=\exp \left(\alpha+(1-\lambda) \varepsilon^{\prime}+\lambda(1-\lambda) \frac{v_{\varepsilon}}{2}\right)-\exp \left(\alpha+\varepsilon^{\prime}\right) .
$$

Note that the dynamics of individual asset income inherit the process for the insurable component of wages, which is iid over time.

\subsection{Welfare analysis with Cobb-Douglas preferences}

We collect the answers to our three welfare questions in the following proposition.

Proposition 1: With Cobb-Douglas preferences the (approximate) welfare effect from a change in labor market risk $\left(\Delta v_{\varepsilon}, \Delta v_{\alpha}\right)$ is:

$$
\omega\left(\Delta v_{\alpha}, \Delta v_{\varepsilon}\right) \simeq-\bar{\gamma} \frac{\Delta v_{\alpha}}{2}+\bar{\phi} \frac{\Delta v_{\varepsilon}}{2}=\underbrace{\bar{\phi} \Delta v_{\varepsilon}}_{\omega^{\text {lev }}} \underbrace{-\bar{\phi} \frac{\Delta v_{\varepsilon}}{2}-\bar{\gamma} \frac{\Delta v_{\alpha}}{2}}_{\omega^{\text {vol }}}
$$

Proof: See Appendix B.

Corollary 1: Let $\chi\left(v_{\alpha}\right)$ denote the (approximate) welfare gain from completing markets in an economy with uninsurable risk variance equal to $v_{\alpha}$. Let $\kappa\left(v_{\alpha}, v_{\varepsilon}\right)$ denote the (approximate) welfare gain from eliminating risk in an economy with variances $\left(v_{\alpha}, v_{\varepsilon}\right)$. Then:

$$
\begin{aligned}
\chi\left(v_{\alpha}\right) & =\omega\left(-v_{\alpha}, v_{\alpha}\right) \simeq \bar{\gamma} \frac{v_{\alpha}}{2}+\bar{\phi} \frac{v_{\alpha}}{2} \\
\kappa\left(v_{\alpha}, v_{\varepsilon}\right) & =\omega\left(-v_{\alpha},-v_{\varepsilon}\right) \simeq \bar{\gamma} \frac{v_{\alpha}}{2}-\bar{\phi} \frac{v_{\varepsilon}}{2}
\end{aligned}
$$

In the Proof of Proposition 1 we derive the exact closed-form solutions for the welfare effects. However, these expressions are cumbersome and not particularly transparent. Through a set of log-approximations of the class $\ln (1+x) \simeq x$ and $e^{x} \simeq 1+x$, one obtains 
the simple and useful solutions stated in Proposition 1. The linearity of the welfare effects in $\Delta v_{\alpha}$ and $\Delta v_{\varepsilon}$ is a feature of the approximation. In Section 7.2 we document the quality of our approximations.

Welfare effect from rising labor market risk $(\omega)$ : The first term in the expression for $\omega$ captures the welfare loss associated with a rise in the dispersion of the uninsurable component of wages. This loss is equal to the expression computed by Lucas (1987) for the welfare costs of aggregate consumption fluctuations in an economy with inelastic labor supply. In particular, the welfare loss is proportional to the risk aversion parameter $\bar{\gamma}$.

The second term signals that increasing insurable productivity dispersion increases welfare in proportion to the Frisch elasticity of labor supply $\bar{\phi}$. The intuition is that given flexible labor supply, an unconstrained planner can achieve better allocative efficiency with larger productivity dispersion, without any loss in terms of consumption smoothing, by commanding longer hours from high-productivity workers and higher leisure from less productive workers. This result is closely related to the one from classical consumer theory stating that the indirect utility function of a static consumer is quasi-convex in prices, so a mean-preserving spread of the price distribution raises welfare (see, for example, Mas Colell et al., 1995, page 59). The complementarity between hours and productivity in production - a very natural assumption - is central in obtaining this result.

In the decomposition of welfare effects into level and volatility components, the level effect, $\omega^{l e v}$, captures the welfare gain associated with the increase in aggregate labor productivity. Why is there a negative volatility effect related to $\Delta v_{\varepsilon}$, notwithstanding full insurance against this source of risk? The reason is that to exploit greater dispersion in productivity across workers, the planner must increase dispersion in hours. Since utility is concave in leisure, this is welfare reducing. At the margin, the welfare gain for the planner from additional specialization in terms of increased average labor productivity is exactly offset by the loss associated with greater dispersion in leisure.

There is no level effect associated to a change in uninsurable wage dispersion because with Cobb-Douglas preferences labor supply is insensitive to uninsurable wage differentials (income and substitution effects exactly offset). The overall welfare impact from additional uninsurable dispersion (i.e., Lucas' expression) is thus equal to the negative volatility effect.

Figure 1 provides a picture of how our welfare effects vary as we change $\theta$, the parameter 
defining agents' willingness to substitute inter-temporally (we hold constant $\eta$, the parameter defining consumption's share in utility). In panel (A) we plot $\omega$ for different values for the inverse of the Frisch elasticity, $\bar{\phi}^{-1}$, which is increasing in $\theta \cdot{ }^{15}$ Raising the Frisch elasticity (reducing $\bar{\phi}^{-1}$ ) reduces the welfare cost of higher dispersion. If labor supply is sufficiently elastic, rising dispersion is actually welfare-improving. In part this finding reflects the fact that the productivity gain associated with larger insurable risk is increasing in the Frisch elasticity, as discussed above. A second effect, working in the same direction, is that with the Cobb-Douglas utility function a higher Frisch elasticity means a lower coefficient of risk aversion (see panel (C)), which in turn implies a lower cost of rising uninsurable risk .

Welfare gain of completing markets $(\chi)$ : Recall that completing markets means (i) a reduction $\Delta v_{\alpha}=-v_{\alpha}$ in the variance of uninsurable risk and (ii) a corresponding increase $\Delta v_{\varepsilon}=v_{\alpha}$ in the variance of insurable risk. The first term in the expression for $\chi$ - proportional to the coefficient of relative risk aversion $\bar{\gamma}$ - captures the value of the additional insurance provided by increased risk-sharing. The second term captures the gains from specialization, whereby more productive households work relatively harder and less productive households enjoy more leisure.

Panel (B) of Figure 1 shows how the welfare gain from completing markets varies with the elasticity of labor supply. Interestingly, the welfare gain is non-monotone. Initially, as the Frisch elasticity falls $(1 / \bar{\phi}$ rises $)$, the welfare gain gets smaller, since it becomes harder to reallocate hours in favor of more productive workers. However, as $\bar{\phi}$ is reduced, $\bar{\gamma}$ rises (panel $(\mathrm{C})$ ), and eventually a point is reached where the value of additional insurance to shelter consumption fluctuations comes to dominate the welfare calculus

Welfare effect from eliminating risk $(\kappa)$ : In a model with exogenous labor supply, there would be no difference between insuring and eliminating idiosyncratic labor income risk. Both changes would lead to income and consumption being equalized across individuals, with no changes in aggregate quantities. With endogenous labor supply, however, increasing risk-sharing is not the same thing as reducing risk at the source. The reason is that additional insurable risk is welfare-improving with a labor supply choice, as discussed above.

\footnotetext{
${ }^{15}$ The values for $\left(v_{\alpha}, v_{\varepsilon}\right)$ and $\left(\Delta v_{\alpha}, \Delta v_{\varepsilon}\right)$ used to produce the plots are from the calibration described in Section 6.1. Plotting welfare effects against $\bar{\phi}^{-1}$ rather than against $\theta$ facilitates comparison with the separable preferences specification. We cannot consider very low values for $\bar{\phi}$ in the context of the CobbDouglas utility specification, since $\lim _{\theta \rightarrow \infty} \bar{\phi}(\theta, \eta)=1-\eta$.
} 
Comparing $\kappa$ with $\chi$, it is clear that the welfare gains from eliminating risk are always smaller than those from insuring risk. Eliminating the uninsured part of wage dispersion is welfare-improving, since this reduces consumption dispersion. However, eliminating dispersion in the insurable component of wages is detrimental, since it eliminates the positive covariance between the insurable component of individual productivity and individual hours that boosts aggregate labor productivity. The cost associated with eliminating insurable dispersion is increasing in the Frisch elasticity, which explains why the gap between $\chi$ and $\kappa$ is decreasing in $\bar{\phi}^{-1}$ in panel (B) of Figure 1.

Our finding that there is a down-side to reducing risk in the presence of flexible labor supply is mirrored in some work on the welfare costs of business cycles. Cho and Cooley (2001) noted that if aggregate hours are pro-cyclical, then eliminating aggregate business cycle risk may reduce average labor productivity. Gomes, Greenwood and Rebelo (2001) provide an example where aggregate fluctuations may be welfare improving in an equilibrium search model when the agent can choose to allocate time between work and search.

Finally, throughout the analysis, we have emphasized that there are benefits and costs to wage inequality. A natural question then arises: Is there an optimal level of inequality? Other authors have addressed this question formally within models where there is a trade-off between inequality and growth (Cordoba and Verdier, 2007) or where inequality has benefits associated to incentive provision (Phelan, 2006). In our framework, the answer depends on whether dispersion is insurable. If it is, inequality is unambiguously good, otherwise it is unambiguously bad.

\section{Separable preferences}

Separability is a common assumption in the micro literature on consumption and labor supply (for a survey, see Browning, Hansen and Heckman, 1999). In this case

$$
u(c, h)=\frac{c^{1-\gamma}}{1-\gamma}-\psi \frac{h^{1+\sigma}}{1+\sigma},
$$

where $\gamma, \sigma \in[0,+\infty)$. The coefficient of relative risk aversion is simply $\gamma$, while the intertemporal elasticity of substitution for consumption is $1 / \gamma$. The Frisch elasticity for labor

supply is simply $1 / \sigma$. In contrast to Cobb-Douglas preferences, separability allows for a 
lot of flexibility in distinguishing between agents' willingness to substitute consumption and hours intertemporally.

Without loss of generality, in what follows we normalize $\psi$, the parameter measuring the distaste for work relative to the taste for consumption, to one. It is easy to verify that such

a normalization has no impact on the welfare expressions. An important implication of this result is that, even if we were to allow for heterogeneity with respect to $\psi$, our final welfare expressions would remain unchanged. Thus our analysis is robust to an important class of preference heterogeneity.

The derivations for equilibrium allocations with separable preferences are described in Appendix C.

\subsection{Equilibrium allocations with separable preferences}

When preferences are separable between consumption and hours worked, equilibrium allocations in the partial-insurance economy are given by:

$$
\begin{aligned}
\log c(\alpha, \varepsilon) & =\left(\frac{1+\sigma}{\gamma+\sigma}\right) \alpha+\left(\frac{1+\sigma}{\gamma+\sigma}\right) \frac{1}{\sigma} \frac{v_{\varepsilon}}{2} \\
\log h(\alpha, \varepsilon) & =\left(\frac{1-\gamma}{\gamma+\sigma}\right) \alpha+\frac{1}{\sigma} \varepsilon-\left(\frac{1+\sigma}{\gamma+\sigma}\right) \frac{\gamma}{\sigma^{2}} \frac{v_{\varepsilon}}{2}
\end{aligned}
$$

The response of hours to permanent shocks is governed by the Marshallian (uncompensated) elasticity of labor supply $(1-\gamma) /(\gamma+\sigma)$. Whether hours increase or decrease with $\alpha$ depends on the relative strength of substitution versus income effects. With separable preferences, the income effect dominates the substitution effect if the risk aversion parameter $\gamma$ is larger than one. The Frisch elasticity $1 / \sigma$ determines the responsiveness of individual hours to insurable shocks to individual wages.

Individual consumption is independent of the realization of the transitory shock $\varepsilon$, reflecting full insurance against this component of the wage process coupled with preferences that are separable between consumption and hours worked. The response of consumption to the uninsurable component of wages is equal to the response of earnings. Since log earnings is equal to log wages plus log hours, the pass-through coefficient from the uninsurable component of wages to earnings is given by $1+(1-\gamma) /(\gamma+\sigma)=(1+\sigma) /(\gamma+\sigma)$. 
As under the Cobb-Douglas specification, individual consumption and leisure also depend on the variance of the insurable component of the log wage, $v_{\varepsilon}$. For any individual state $(\alpha, \varepsilon)$, both consumption and leisure are increasing in $v_{\varepsilon}$.

\subsection{Welfare analysis with separable preferences}

We now state a pair of propositions analogous to Propositions 1 and 2.

Proposition 1a: With separable preferences the (approximate) welfare effect from a change in labor market risk $\left(\Delta v_{\varepsilon}, \Delta v_{\alpha}\right)$ is:

$$
\begin{aligned}
\omega\left(\Delta v_{\alpha}, \Delta v_{\varepsilon}\right) & \simeq-\left[\frac{\gamma-1}{\gamma+\sigma}+\gamma\left(\frac{1+\sigma}{\gamma+\sigma}\right)\right] \frac{\Delta v_{\alpha}}{2}+\frac{1}{\sigma} \frac{\Delta v_{\varepsilon}}{2} \\
& =\underbrace{-\frac{\gamma-1}{\gamma+\sigma} \Delta v_{\alpha}+\frac{1}{\sigma} \Delta v_{\varepsilon}}_{\omega^{\text {lev }}}+\underbrace{+\left[\frac{\gamma-1}{\gamma+\sigma}-\gamma\left(\frac{1+\sigma}{\gamma+\sigma}\right)\right] \frac{\Delta v_{\alpha}}{2}-\frac{1}{\sigma} \frac{\Delta v_{\varepsilon}}{2}}_{\omega^{\text {vol }}} .
\end{aligned}
$$

Proof: See Appendix D.

Corollary 1a: With separable preferences, the (approximate) welfare gains from completing markets and from eliminating risk in an economy with variances $\left(v_{\alpha}, v_{\varepsilon}\right)$ are given, respectively, by:

$$
\begin{aligned}
\chi\left(v_{\alpha}\right)=\omega\left(-v_{\alpha}, v_{\alpha}\right) & \simeq\left[\frac{\gamma-1}{\gamma+\sigma}+\gamma\left(\frac{1+\sigma}{\gamma+\sigma}\right)\right] \frac{v_{\alpha}}{2}+\frac{1}{\sigma} \frac{v_{\alpha}}{2} \\
\kappa\left(v_{\alpha}, v_{\varepsilon}\right) & =\omega\left(-v_{\alpha},-v_{\varepsilon}\right) \simeq\left[\frac{\gamma-1}{\gamma+\sigma}+\gamma\left(\frac{1+\sigma}{\gamma+\sigma}\right)\right] \frac{v_{\alpha}}{2}-\frac{1}{\sigma} \frac{v_{\varepsilon}}{2}
\end{aligned}
$$

Welfare effect from rising labor market risk $(\omega)$ : As with Cobb-Douglas preferences, increasing insurable productivity dispersion strictly increases welfare in proportion to the Frisch elasticity. Once again, the intuition is simply that an unconstrained planner can achieve better allocative efficiency with larger dispersion by having the more productive agents specialize in market work. An interesting difference between the two preference specifications is that when preferences are separable, the productivity gain associated with greater wage dispersion translates into higher average consumption, whereas in the Cobb-Douglas 
case productivity gains have no impact on average consumption, but translate into higher welfare through an increase in average leisure. ${ }^{16}$

The welfare effects of a rise in uninsurable uncertainty are more complex. When $\gamma>1$, the income effect from a positive wage shock dominates the substitution effect, so agents increase work effort in bad times. In this case, flexible labor supply is used to improve consumption smoothing at the expense of productivity (the level effect is negative). When $\gamma<1$, the substitution effect dominates the income effect, and agents increase work effort in good times. In this case, flexible labor supply actually increases consumption volatility, but it is still beneficial because agents are relatively unconcerned about fluctuations in consumption, and concentrating work effort in high wage periods raises average output per hour (the level effect is positive). In light of our discussion, we conclude that for flexible labor supply to mitigate the welfare cost of increases in uninsurable wage risk, it must be the case that $\gamma \neq 1$, implying that preferences are inconsistent with balanced growth.

For $\gamma \geq 1$, the expression for $\omega$ indicates that additional uninsurable risk is unambiguously welfare-reducing. However, a surprising finding is that when $\gamma<1 /(2+\sigma)$, a rise in $v_{\alpha}$ has a positive welfare effect. ${ }^{17}$ The intuition is that when risk aversion is sufficiently small and the labor supply elasticity sufficiently large, agents willingly substitute labor supply intertemporally to raise average productivity, and are relatively unconcerned about the resulting fluctuations in consumption. Two interesting benchmarks are $\gamma=0$, in which case $\omega=(1 / 2)(1 / \sigma)\left(\Delta v_{\alpha}+\Delta v_{\varepsilon}\right)$, and $\gamma=\sigma=1$, in which case $\omega=(1 / 2)\left(-\Delta v_{\alpha}+\Delta v_{\varepsilon}\right)$

Panel (A) of Figure 2 provides a graphical summary of how the overall cost of rising dispersion, $\omega$, varies with risk aversion, $\gamma$, and the inverse of the Frisch elasticity, $\sigma$.

Welfare gains from completing markets $(\chi)$ : As in the Cobb-Douglas case, there are two sources of welfare gains from insuring risk. The first is the gain from the additional insurance provided by increased risk sharing. The second is the allocative efficiency gain associated with elastic labor supply: under complete markets, more productive households work relatively longer hours and less productive households enjoy more leisure.

The welfare gain from completing markets is strictly increasing in $\gamma$, the degree of risk-

\footnotetext{
${ }^{16}$ This can be easily seen by computing $\mathbb{E}[c(\alpha, \varepsilon)]$ and $\mathbb{E}[1-h(\alpha, \varepsilon)]$ under both preference specifications. See Appendix B for the Cobb-Douglas case, and Appendix D for the separable case.

${ }^{17}$ Recall that in the Cobb-Douglas case, increases in uninsurable wage dispersion $v_{\alpha}$ always reducing welfare.
} 
aversion. A few benchmarks are of interest. First, for $\gamma=0$ (risk-neutrality), the welfare gain is exactly zero, since consumption fluctuations are not costly. Second, in the absence of flexible labor supply $(\sigma \rightarrow \infty)$, the welfare gain is $\chi \simeq \gamma v_{\alpha} / 2$, the Lucas expression for the welfare cost of consumption fluctuations. Third, if $\gamma=\sigma=1$, then $\chi \simeq v_{\alpha}$.

Panel (B) of Figure 2 documents that $\chi$ is non-monotone in $\sigma$. For $\sigma<1, \chi$ is always increasing in the Frisch elasticity. However, for $\sigma \geq 1$, whether or not $\chi$ is increasing in the Frisch elasticity depends on whether $\gamma \leq 2 \sigma /(\sigma-1)$. The intuition is that, given high aversion to consumption fluctuations, an increase in the willingness to substitute hours intertemporally can have a larger positive impact on welfare under autarky (by effectively improving self-insurance) than under complete markets (by increasing average productivity).

Welfare effect from eliminating risk $(\kappa)$ : As in the Cobb-Douglas specification, eliminating labor market risk amounts to reducing to zero the variances of both components of the wage process, which is welfare reducing for insurable risk, and likely welfare-improving for uninsurable risks. Comparing panels (B) and (C) of Figure 2 it is clear that the welfare gains from eliminating risk are similar to those from completing markets when the Frisch elasticity is low ( $\sigma$ is high), but are much smaller - and in some cases negative - when the Frisch elasticity is high.

\section{Observables-based welfare analysis}

It is possible to derive alternative representations for the welfare effects of rising inequality (and for the level and volatility components) as functions only of preference parameters and second moments of the joint cross-sectional distribution for wages, hours and consumption.

The key advantage of these observables-based expressions, relative to the parametric expressions described above, is that they are more general. They can be applied to any economy in which (i) the standard intratemporal optimality condition between consumption and leisure/hours worked is satisfied, and (ii) wages, consumption and leisure/hours are jointly log-normal. Moreover, in order implement the observables-based approach, we do not need estimates for how the variances of uninsurable versus insurable wages risks have changed over time, $\left(\Delta v_{\alpha}, \Delta v_{\varepsilon}\right){ }^{18}$ Thus we can estimate welfare effects simply by computing

\footnotetext{
${ }^{18}$ Within the context of our particular model economy, information about these parameters is effectively embedded in the evolution of equilibrium cross-sectional moments.
} 
the relevant moments in repeated cross-sections and assigning values to preference parameters. However, the observables-based approach requires high-quality data on consumption and hours, while the model-based approach only requires panel data on wages. We therefore view the two alternative approaches as complementary.

The following assumptions are convenient.

Assumption A1: Preferences are Cobb-Douglas and wages w, consumption c, and leisure $1-h$ are log-normally distributed in the cross-section.

Assumption A1': Preferences are separable and wages $w$, consumption $c$, and hours worked $h$ are log-normally distributed in the cross-section.

Assumption A2: Wages and allocations satisfy individual intratemporal optimality, aggregate consumption equals aggregate labor income, and the average wage equals one (so $\mathbb{E}[\log w]=-\operatorname{var}(\log w) / 2)$.

We are now ready to state the main result of this section.

Proposition 2: Under Assumptions A1-A2 and A1'-A2 the (approximate) welfare effect $\omega$ of a rise in wage dispersion can be expressed as:

$\omega \simeq \underbrace{\Delta \operatorname{cov}(\log w, \log h)}_{\omega^{\text {lev }}} \underbrace{-\frac{1}{2}\left(-\frac{u_{C C} C}{u_{C}}\right) \Delta \operatorname{var}(\log c)-\frac{1}{2}\left(\frac{u_{H H} H}{u_{H}}\right) \Delta \operatorname{var}(\log h)+\frac{u_{C H} H}{u_{C}} \Delta \operatorname{cov}(\log c, \log h)}_{\omega^{\text {vol }}}$, where $C=\mathbb{E}(c)$ and $H=\mathbb{E}(h)$. In the Cobb-Douglas case we have

$$
-\frac{u_{C C} C}{u_{C}}=\bar{\gamma}, \quad \frac{u_{H H} H}{u_{H}}=\bar{\gamma}-1+\frac{\eta}{1-\eta}, \quad \text { and } \frac{u_{C H} H}{u_{C}}=\bar{\gamma}-1
$$

and in the separable case, we have

$$
-\frac{u_{C C} C}{u_{C}}=\gamma, \quad \frac{u_{H H} H}{u_{H}}=\sigma, \quad \text { and } \frac{u_{C H} H}{u_{C}}=0
$$

Moreover, the level effect $\omega^{\text {lev }}$ (approximately) equals the percentage change in aggregate labor productivity $\Delta \log (C / H)$.

Proof: See Appendix E. 
The expression for $\omega$ in Proposition 2 comprises four terms. The first term is the change in the covariance between hours and wages: a higher positive correlation between individual hours and individual productivities improves the level of aggregate welfare. This change in the covariance is equal to the level effect $\omega^{\text {lev }}$ as defined in (5), and can also be shown to equal the change in aggregate labor productivity in the economy.

The second and third terms capture the volatility cost of a rise in wage dispersion: an increase in the variance of log consumption translates into a welfare cost proportional to the risk-aversion coefficient, and an increase in the variance of log hours translates into a welfare cost that is proportional to the coefficient $u_{H H} H / u_{H}$, which measures aversion to hours fluctuations. In the separable case, this term is exactly the inverse of the Frisch elasticity, $\sigma$. In the Cobb-Douglas case, when $\eta=1 / 2$ (consumption and leisure receive equal weight in utility), it is equal to the risk-aversion coefficient $\bar{\gamma}$.

The fourth term, involving the change in the covariance between consumption and hours worked, is only present when utility is non-separable in consumption and leisure. It is zero in the separable case and when the Cobb-Douglas utility function becomes "log-log", i.e., for $\theta=1$. In the Cobb-Douglas case, when $\theta>1$ (which implies $\bar{\gamma}>1$ ), consumption and leisure (hours worked) are substitutes (complements); thus households gain from a rise in the comovement between consumption and hours worked.

Clearly, our model economy satisfies Assumptions A1-A2. Indeed, one can easily use our closed-form equilibrium allocations to compute analytical expressions for cross-sectional moments as a function of preference parameters and variances of uninsurable and insurable shocks $\left(v_{\alpha}, v_{\varepsilon}\right)$. Substituting these expressions into the welfare representation of Proposition 2, and rearranging terms, yields the model-based welfare effects of Propositions 1 and 1a.

A word on the approximations implicit in Proposition 2 is in order. The derivations in Appendix E show that we can reach exact observables-based representations for both preference specifications. However, while the one for the separable case is in terms of hours worked, the one for the Cobb-Douglas case is in terms of leisure. In order to obtain the common representation for welfare change in Proposition 2, one needs to take an approximation, in the Cobb-Douglas case, in order to to translate cross-sectional moments involving leisure into moments involving hours worked.

Assumptions A1 and A1' can be relaxed. In fact, the observables-based expression for 
the welfare effect in equation in can alternatively be obtained from a second-order Taylor approximation of any continuously differentiable concave utility function (where the Taylor approximation is taken over $\log c$ and $\log h$ around the average consumption and hours worked). Log normality of the allocations is required to show that the welfare gain from changes in aggregate consumption and leisure - the level effect - is approximately equal to the change in the covariance between log hours and log wages. Details are available upon request.

\section{Quantitative welfare analysis}

\subsection{Calibration and measurement}

First we discuss our baseline choices for preference parameters. Next we discuss the crosssectional moments of the joint wage, hours and consumption distribution which we use to implement our alternative observables-based approach to quantifying the welfare effects of rising wage dispersion, given the expressions in Proposition 2. Finally, we estimate the variances of insurable and uninsurable wage risk before $\left(v_{\alpha}, v_{\varepsilon}\right)$ and after $\left(\widehat{v}_{\alpha}, \widehat{v}_{\varepsilon}\right)$ the recent well-documented surge in wage dispersion (see Katz and Autor, 1999; Eckstein and Nagypal 2004, for empirical surveys). These variances are a key input of our model-based welfare expressions of Propositions 1 and 1a.

Preference parameters: We begin with the separable case. Estimates for the riskaversion coefficient $\gamma$ (or, identically, for the inverse of the intertemporal labor supply elasticity) between one and three are typical in the empirical consumption literature (see Attanasio, 1999, for a survey), so we set $\gamma=2$. Domeij and Flodén (2006) sample the empirical literature on male labor supply and conclude that the typical estimates of Frisch elasticities for male labor supply range between 0.1 and 0.3 . However, they argue that these estimates are downward-biased because the standard estimation methods ignore the possibility that borrowing constraints may bind. By simulation, they show that the unbiased estimates can be up to twice as large. Moreover, estimates of this elasticity for females are, in general, 3-4 times as large as those for men (see Blundell and MaCurdy, 1999, Table 2). We therefore set the Frisch elasticity to 0.5 , corresponding to $\sigma=2$. 
With Cobb-Douglas utility, the Frisch labor supply elasticity and the coefficient of riskaversion are not independent since they are both functions of the pair of parameters $(\theta, \eta)$, as discussed in Section 4.2. Moreover, the parameter $\eta$ has a natural counterpart in the fraction of the time endowment devoted to work activities. Following the macroeconomic literature on business cycles, we set $\eta=1 / 3$ (see e.g. Cooley, 1995). ${ }^{19}$ We then set $\theta=4$ so the implied coefficient of risk-aversion $\bar{\gamma}$ equals two, as in the separable case. As a by-product, we obtain a Frisch elasticity $\bar{\phi}$ equal to one - a higher number than in the separable case. ${ }^{20}$

We recognize that there is disagreement regarding appropriate values for preference parameters, and that some may object to our particular choices. One advantage of our closedform expressions for welfare is that one can easily plug in alternative values. We present results for a large set of alternative parameterizations in Figures 1 and 2.

Measurement of wage, hours and consumption dispersion: From the 1968-1997 waves of the Panel Study of Income Dynamics (PSID), we select a sample of roughly 2,400 observations/year including every head of household aged between 20 and 59 with positive earnings (not top-coded and not below half of the current minimum wage), and with annual hours worked between 520 and $5824 .^{21}$ We compute hourly wages as annual pre-tax earnings divided by annual hours worked, and we regress both wages and hours on race dummies and a quartic in age in order to filter out predictable life-cycle variation. ${ }^{22}$ We construct variances and covariances on the $(\log )$ residuals of these regressions. We find that the variance of $\log$ wages rose by 0.10 (from 0.25 to 0.35 ) over this time period, the variance of log-hours worked rose by 0.01 (from 0.082 to 0.092 ), and the covariance between hours and wages rose by 0.017 (from -0.023 to -0.006 ).

For consumption dispersion, we rely on existing studies based on the Consumer Expen-

\footnotetext{
${ }^{19}$ More precisely, the first-order condition for hours worked in a non-stochastic version of the model implies $h=\eta$.

${ }^{20}$ We chose to equate the coefficient of risk aversion across alternative preference specifications, rather than the Frisch elasticity for labor supply, because the lower bound on the Frisch elasticity under the Cobb-Douglas specification is $\bar{\phi}=1-\eta=2 / 3$.

${ }^{21}$ This latter restriction serves the purpose of reducing the extent to which measurement error in hours, which is well known to be pervasive, can affect our statistics. In general, the levels of variances and covariances are potentially affected by measurement error. However, as long as the measurement error 1) is multiplicative in levels, 2) is orthogonal to the true value, and 3) exhibits constant variance over the period, then the changes in these measured cross-sectional moments, which are the inputs to our cross-sectional calculations, will not be affected.

${ }^{22}$ This first-stage regression ensures consistency with the consumption data, since Krueger and Perri (2006) report cross-sectional variances for log consumption using residuals from a similar regression.
} 
diture Survey (CEX). For consistency with individual wage and hours data, we focus on consumption data expressed in adult-equivalent units. According to Slesnick (2001), the rise in the variance of log-consumption between 1980 and 1995 was small, around 0.01 (0.20 in 1980, 0.21 in 1995). Krueger and Perri (2006) and Attanasio, Battistin and Ichimura (2004) argue that consumption inequality rose by about 0.05 over the same period. Since there are important measurement issues that are not yet settled in this literature, we simply adopt a mid-point estimate of 0.03 for our calculations. Finally, Krueger and Perri (2003) report that the covariance between hours and consumption declined by 0.007 (from 0.037 to 0.030 ). ${ }^{23}$

Measurement of insurable/uninsurable wage components: We estimate a simple permanent/transitory model for the variance of log wages, exactly the process specified in the description of the model economy. The estimated variance of the transitory/insurable component $v_{\varepsilon}$ starts around 0.08 in the late 1960s and levels off thirty years later at around 0.13. The variance of the permanent/uninsurable component $v_{\alpha}$ starts at a value around 0.17 and rises to 0.22 in the mid 1990s. In light of these results, we set $\Delta v_{\varepsilon}=\Delta v_{\alpha}=0.05$ when evaluating the welfare implications of rising dispersion. Moreover, focusing on the levels of labor market uncertainty for the $1990 \mathrm{~s}$, we set $v_{\alpha}=0.22$ and $v_{\varepsilon}=0.13$. $^{24}$

An alternative approach to estimating $\left(\Delta v_{\varepsilon}, \Delta v_{\alpha}\right)$ would involve using expressions for the variances and covariances of wages, hours and consumption, which can be derived in closedform given the equilibrium decision rules in Sections 4 and 5 . The idea is that observed changes in second moments involving endogenous variables are informative about changes in the variances of underlying insurable and uninsurable shocks. We pursue this strategy in a companion paper (Heathcote, Storesletten and Violante, 2007b) and find that it delivers a similar breakdown of increased cross-sectional wage dispersion into insurable and uninsurable components.

\footnotetext{
${ }^{23}$ Note that our PSID sample has an earlier start date than the CEX, which is only available on a consistent basis since 1980. Fortunately, almost all of the observed rise in wage inequality occurred after this date.

${ }^{24}$ Our findings can be summarized as follows: (i) the transitory component accounts for roughly $1 / 3$ of the total dispersion; (ii) the rise in wage dispersion is accounted equally by the two components. These results are broadly in line with the findings by Gottschalk and Moffitt (1994).
} 
Table 1: Welfare Effects (\% of lifetime consumption)

\begin{tabular}{|c|c|c|c|c|c|c|}
\hline \multicolumn{3}{|c|}{$\begin{array}{l}\text { Welfare effect of } \\
\text { rise in wage dispersion }\end{array}$} & \multirow{2}{*}{\multicolumn{2}{|c|}{$\begin{array}{l}\text { Welfare gain from } \\
\text { completing markets }\end{array}$}} & \multirow{2}{*}{\multicolumn{2}{|c|}{$\begin{array}{l}\text { Welfare effect from } \\
\text { eliminating risk }\end{array}$}} \\
\hline model-based & \multicolumn{2}{|c|}{ observables-based } & & & & \\
\hline \multicolumn{7}{|c|}{ Cobb-Douglas Preferences } \\
\hline \multirow{2}{*}{$\begin{array}{c}\omega \\
-2.47 \%(-2.50 \%)\end{array}$} & \multirow{2}{*}{\multicolumn{2}{|c|}{$\begin{array}{c}\omega \\
-2.75 \%\end{array}$}} & \multicolumn{2}{|c|}{$\chi$} & \multicolumn{2}{|c|}{$\kappa$} \\
\hline & & & $+39.1 \%$ & $+33.0 \%)$ & $+16.9 \%$ & $+15.5 \%)$ \\
\hline $\begin{array}{cc}\text { Volat. } & \text { Level } \\
-7.50 \% & +5.00 \%\end{array}$ & $\begin{array}{l}\text { Volat. } \\
-4.45 \%\end{array}$ & $\begin{array}{l}\text { Level } \\
+1.70 \%\end{array}$ & $\begin{array}{l}\text { Volat. } \\
+11.0 \%\end{array}$ & $\begin{array}{l}\text { Level } \\
+22.0 \%\end{array}$ & $\begin{array}{l}\text { Volat. } \\
+28.5 \%\end{array}$ & $\begin{array}{c}\text { Level } \\
-13.0 \%\end{array}$ \\
\hline \multicolumn{7}{|c|}{ Separable Preferences } \\
\hline$\omega$ & \multicolumn{2}{|c|}{$\omega$} & \multicolumn{2}{|c|}{$\chi$} & \multicolumn{2}{|c|}{$\kappa$} \\
\hline$-3.06 \%(-3.13 \%)$ & \multicolumn{2}{|c|}{$-2.30 \%$} & \multicolumn{2}{|c|}{$+29.2 \%(+24.8 \%)$} & \multicolumn{2}{|c|}{$+17.8 \%(+16.0 \%)$} \\
\hline $\begin{array}{cc}\text { Volat. } & \text { Level } \\
-4.38 \% & +1.25 \%\end{array}$ & $\begin{array}{l}\text { Volat. } \\
-4.00 \%\end{array}$ & $\begin{array}{c}\text { Level } \\
+1.70 \%\end{array}$ & $\begin{array}{l}\text { Volat. } \\
+8.3 \%\end{array}$ & $\begin{array}{l}\text { Level } \\
+16.5 \%\end{array}$ & $\begin{array}{l}\text { Volat. } \\
+17.0 \%\end{array}$ & $\begin{array}{l}\text { Level } \\
-1.0 \%\end{array}$ \\
\hline
\end{tabular}

\subsection{Results}

We summarize our results in Table 1. To gauge the quality of our approximations relative to the exact welfare expressions contained in the Appendix, we also report, in parentheses, the values implied by the approximated welfare expressions described in Propositions 1 and 1a. Below the total welfare changes, we report the decomposition of our approximated welfare effects into level and volatility components.

Welfare effects of rising dispersion, model-based approach: The welfare losses associated with the observed rise in wage dispersion are quite similar across the two preferences specifications, between $2.5 \%$ and $3 \%$ of lifetime consumption. With Cobb-Douglas preferences, the welfare loss due to the volatility component is $7.5 \%$ of lifetime consumption, while the partially offsetting welfare gain due to improved aggregate labor productivity is $5 \%$. With separable preferences both components are smaller in absolute value. One reason is that the Frisch elasticity is lower under the separable specification, which implies that additional insurable risk translates into a smaller increase in hours dispersion, and a smaller increase in aggregate productivity. ${ }^{25}$

\footnotetext{
${ }^{25}$ In addition, the fact that $\gamma>1$ means that additional uninsurable risk reduces average labor productivity
} 
Welfare effects of rising dispersion, observables-based approach: For the separable preferences case (assuming $\gamma=\sigma=2$ ), one can easily plug in the observed changes in the variances of hours, consumption, and in the covariance between hours and wages to obtain $\omega=-2.3 \%$. A similar computation for the Cobb-Douglas case (for which we also need the change in the covariance between hours and consumption) yields $\omega=-2.75 \%$.

These estimates are very close to those from the model-based approach, which is encouraging given that the two sets of calculations rely on very different inputs. The reason for the broad correspondence between the two sets of welfare numbers is that viewed through the lens of our model, the observed changes over time in empirical cross-sectional variances and covariances for wages, hours and consumption point to values for $\left(\Delta v_{\varepsilon}, \Delta v_{\alpha}\right)$ that are very close to the ones we used as inputs to the model-based welfare calculations, i.e., $(0.05,0.05)$.

Krueger and Perri (2003) propose evaluating welfare effects using individual consumption data. Using the panel-dimension of CEX, they estimate Markov transition matrices for consumption and hours worked in two sub-samples (before and after the rise in wage inequality) and use these stochastic processes directly into preferences to compute welfare effects. However, in constructing their data, they abstract from the level effect by demeaning all observations, so their calculations should be compared to our volatility effect. They assume Cobb-Douglas preferences and set $\bar{\phi}=\bar{\gamma}=1.33$. Given the observed changes in $\operatorname{cov}(\log h, \log w), \operatorname{var}(\log c)$ and $\operatorname{var}(\log h)$, this parameterization maps into a volatility effect of $\omega^{v o l}=-2.5 \%$, which is quite close to their estimated welfare loss of $-2.1 \%{ }^{26}$

From Proposition 2 it follows that the degree to which a society is able to allocate labor efficiently - labor productivity - has the simple empirical representation cov $(\log h, \log w)$, irrespective of preferences. In our PSID sample, labor productivity, measured as the ratio of aggregate earnings to aggregate hours, increased by $13 \%$ from 1975 to 1995. Thus, the increase in the wage-hours covariance $(1.7 \%)$ can alone account for more than a tenth of the increase in aggregate labor productivity over this period.

Welfare gains from completing markets: With Cobb-Douglas preferences, a household in the partial-insurance economy values the availability of a complete set of insurance

when preferences are separable, partially offsetting the positive effect of additional insurable risk, since strong wealth effects induce permanently more productive agents to increase leisure.

${ }^{26}$ We obtain this number as follows. They report that when using consumption data only, welfare losses are of the order of $-1.6 \%$. Incorporating leisure into their analysis subtracts another $0.5 \%$ from their benchmark estimate. 
markets against the permanent component of wages at $39 \%$ of her lifetime consumption. With separable preferences, this estimate is smaller, around 29\%. The striking feature of these results is that, in both cases, the gains associated with better productive opportunities in complete markets are twice as big as the gains from reduced dispersion. Recall that in the separable case, since $\gamma>1$, households with low permanent (uninsurable) wage components work longer hours than those with high permanent components. However, efficiency dictates a positive correlation between wages and hours. Our calculations indicate that the aggregate productivity loss due to this inefficient assignment is huge, accounting for two thirds of the welfare cost of market incompleteness.

Attanasio and Davis (1996, Table 6) calculated the gains from insuring all consumption risk between age/educational groups to be around $2.67 \%$ for a risk aversion value of 2 . This number is an order of magnitude lower than ours for two reasons. First, the data show a large amount of consumption dispersion even within groups that we capture in our calculations. Second, by abstracting from labor supply, they miss what we find to be the largest source of welfare gains from completing markets.

Welfare gains from eliminating risk: It is instructive to compare quantitatively the welfare gains from eliminating labor market risk to those from insuring risk. In the CobbDouglas case we obtain $\kappa=16.9 \%$, compared to $\chi=39.1 \%$. Thus, eliminating risk implies a welfare gain less than half as large as the welfare gain from completing markets. The corresponding numbers for the separable preferences case are $\kappa=17.8 \%$ and $\chi=29.2 \%$.

The fact that eliminating the insurable component of wage risk is welfare-reducing leaves open the theoretical possibility that the welfare effect from eliminating all idiosyncratic wage risk through some redistributive policy might be negative. In our calibration to the United States, however, most wage dispersion is uninsurable in nature, and given plausible choices for preference parameters, the welfare gains from eliminating uninsurable risk exceed the costs of eliminating insurable risk.

\subsection{Relation to numerically-solved Bewley models}

How do the results from our analytical model compare to standard incomplete-market models relying on self insurance through hours worked and borrowing and lending? To provide a natural and comparable benchmark, we compute the equilibrium of an economy identical 
to our partial-insurance model, except that instead of having access to a complete set of state-contingent claims providing perfect insurance against transitory wage shocks, agents trade only a non-contingent bond (e.g., Bewley, 1986; Imrohoroglu, 1989; Huggett, 1993; Aiyagari, 1994; Ríos-Rull, 1994). At the aggregate level, bonds are in zero net supply.

In the Bewley economy, the welfare effect associated with an increase in wage dispersion will depend on two additional parameters that could be left unspecified in the partialinsurance model: the borrowing limit, and the discount factor $\beta{ }^{27}$ The borrowing constraint is set to the "natural" limit (see, for example, Aiyagari, 1994) which ensures that interest payments never exceed earnings, given maximum labor effort. Preferences are Cobb-Douglas and the discount factor is $\beta=0.97$, which implies a final steady state interest rate of $3.05 \%$. The expected welfare effects are computed for individuals born with zero wealth who draw lifetime wage profiles at random from the unconditional wage distribution.

The expected welfare effect in the Bewley economy associated with the measured rise in wage dispersion is a $2.77 \%$ loss. This number should be compared to the $2.37 \%$ loss in our partial-insurance economy. ${ }^{28}$ Increases in wage risk are slightly more costly in the model with a single bond, because with a positive interest rate a transitory wage shock has some effect on lifetime income. Nevertheless, the two models deliver surprisingly similar answers to our main welfare question.

For comparisons with other papers, consider e.g. Pijoan-Mas (2005). He calculates the welfare gain from completing markets to be about $16 \%$ of lifetime consumption in an infinitely-lived-agent, production economy with separable preferences and flexible labor supply. Since fixed effects implicitly remain uninsured under his interpretation of what it means for markets to be complete, this number should be compared to the welfare gain of moving from autarky to an environment where the transitory component of wages is fully insured, while the permanent component remains uninsured (i.e. the partial-insurance economy). This is given by $\omega\left(-v_{\varepsilon}, v_{\varepsilon}\right)$. Setting $\gamma=0.98$ and $\sigma=0.61$ (the parametrization used by

\footnotetext{
${ }^{27}$ Levine and Zame (2002) study an endowment economy with infinitely-lived agents, CRRA preferences, and a non-contingent bond as the only traded asset. They show that as the discount rate goes to zero, agents achieve arbitrarily good insurance against non-permanent shocks.

${ }^{28}$ To solve this model numerically, both the permanent component of the wage $\alpha$ and the transitory component $\varepsilon$ are drawn from symmetric two-point distributions. Given this two-point distribution, the welfare effect from increased wage dispersion in our benchmark partial-insurance economy is $-2.37 \%$ as compared to the $-2.47 \%$ loss reported in Table 1 for the continuous Normal distribution. More details on the numerical implementation are available upon request.
} 
Pijoan-Mas) gives $18.6 \%$.

We conclude that our simple and transparent framework can shed light on the economics underlying numerical findings in richer models in the Bewley tradition.

However, our framework cannot be expected to match the quantitative welfare effects when additional channels of opportunities and insurance are introduced, over and above savings and hours worked. For example, in Heathcote et al. (2007a), we explore two additional choices that allow households to increase average labor productivity and mitigate the welfare loss in response to changes in the wage structure: the flexibility to adjust enrollment decisions in response to a widening college premium, and the flexibility to reallocate market work within the household in response to a narrowing gender wage gap.

\section{Concluding remarks}

The main contributions of the paper are (1) the analytical characterization of the welfare effects from an increase in the dispersion of labor productivity, and (2) the focus on the role of endogenous labor supply. In addition, welfare effects are shown to have a common representation in terms of observable second moments (variances and covariances) of the joint equilibrium distribution of wages, hours worked and consumption. This is true for both Cobb-Douglas and separable preferences,

Our analytical insights, together with a simple calibration exercise, show that eliminating idiosyncratic wage risk implies a welfare gain that is at least two orders of magnitude larger than most estimates of the welfare gains from eliminating business cycle risk. Thus, according to our model, the potential gain for a society from applying progressive taxes and wage compression is much larger than the potential gain from obtaining aggregate stabilization.

However, we also emphasized that the welfare gains from eliminating wage risk (through policies that compress after-tax wages) are only around half as large as the gains that would accrue from perfectly insuring wage risk. From a policy perspective, an important implication is that the government should develop the legal and institutional frameworks that will allow new insurance markets to develop. Sargent (2001) and Shiller (2003) discuss a range of proposals along these lines. ${ }^{29}$

\footnotetext{
${ }^{29}$ For example, Shiller proposed six types of insurance that should be further developed, namely "livelihood
} 
Throughout the analysis, income shocks have been assumed to be verifiable and contracts have been assumed to be perfectly enforceable. Informational asymmetries and imperfect commitment may limit the amount of insurance that one could ever hope to see provided. In this sense, our estimates of the welfare costs of market incompleteness are upper bounds. At the same time, to the extent that risk sharing is limited by fundamental frictions, these frictions can interact with changes in labor market risk in interesting ways. For example, Krueger and Perri (2006) study a calibrated endowment economy in which debt contracts can only be imperfectly enforced. They show that a rise in income dispersion might increase welfare by making default more painful, thereby increasing the amount of credit that can be supported in equilibrium. The implications of increased labor market risk in a private information environment have not yet been addressed. More broadly, an important challenge in introducing these sorts of frictions is to do this in a way that maintains tractability, thereby allowing for a transparent characterization of the various mechanisms at work.

Finally, the trade-off between insurance and opportunities emphasized in relation to the labor supply decision could also apply to other margins of adjustment. For example, the widening gap between the wages of college and high-school graduates offers opportunities to increase average earnings if agents can respond by extending their education. As discussed above, Heathcote et al. (2007a) incorporates an explicit education choice, and explore how introducing this margin of adjustment (as well as explicit labor supply decisions in two-member households) mediates the effect of changes in the wage structure on labor productivity and welfare.

insurance", "home equity insurance", "macro markets", "income-linked loans", "inequality insurance" and "intergenerational social security". 


\section{Appendix}

Appendix A: Derivation of Equilibrium Allocations (Cobb-Douglas Utility)

We follow the " $\alpha$-island representation" of our economy outlined at the end of Section 2. We start by guessing that agents on different $\alpha$-islands do not trade with each other. This allows us to solve for allocations within islands using an island-planner problem. Next, we verify our guess.

The static equal-weight planner problem for an island indexed by a specific value of $\alpha$ can be written as

$$
\max _{\{c(\alpha, \varepsilon) h(\alpha, \varepsilon)\}} \int_{E} u(c(\alpha, \varepsilon) h(\alpha, \varepsilon)) d \Phi_{v_{\varepsilon}}(\varepsilon)
$$

subject to a static resource constraint that reflects the absence of inter-island trade and the lack of a storage technology

$$
\int_{E} w(\alpha, \varepsilon) h(\alpha, \varepsilon)-c(\alpha, \varepsilon) d \Phi_{v_{\varepsilon}}(\varepsilon)=0 .
$$

With Cobb-Douglas utility, the planner's first-order condition for hours is

$$
w(\alpha, \varepsilon) h(\alpha, \varepsilon)=w(\alpha, \varepsilon)-c(\alpha, \varepsilon) \frac{1-\eta}{\eta} .
$$

Substituting the right-hand side of this latter equation into equation (14) and collecting terms determines total consumption on the island

$$
\int_{E} c(\alpha, \varepsilon) d \Phi_{v_{\varepsilon}}(\varepsilon)=\eta \int_{E} w(\alpha, \varepsilon) d \Phi_{v_{\varepsilon}}(\varepsilon)=\eta \exp (\alpha) .
$$

The first-order condition for consumption is

$$
\mu=\eta c(\alpha, \varepsilon)^{\eta(1-\theta)-1}(1-h(\alpha, \varepsilon))^{(1-\eta)(1-\theta)},
$$

where $\mu$ is the Lagrange multiplier on the resource constraint (14). Using (15) to substitute out for leisure in (17) and rearranging gives

$$
c(\alpha, \varepsilon)=\left(\frac{\eta}{\mu}\right)^{1 / \theta}\left(\frac{1-\eta}{\eta}\right)^{(1-\eta)(1-\theta) / \theta} w(\alpha, \varepsilon)^{-(1-\eta)(1-\theta) / \theta} .
$$

Integrating (18) across the population yields an alternative expression for total consumption

$$
\begin{aligned}
\int_{E} c(\alpha, \varepsilon) d \Phi_{v_{\varepsilon}}(\varepsilon) & =\left(\frac{\eta}{\mu}\right)^{\frac{1}{\theta}}\left(\frac{1-\eta}{\eta}\right)^{\frac{(1-\eta)(1-\theta)}{\theta}} \int_{E} \exp \left(-\frac{(1-\eta)(1-\theta)}{\theta}(\alpha+\varepsilon)\right) d \Phi_{v_{\varepsilon}}(\varepsilon) \\
& =\left(\frac{\eta}{\mu}\right)^{\frac{1}{\theta}}\left(\frac{1-\eta}{\eta}\right)^{\frac{(1-\eta)(1-\theta)}{\theta}} \exp \left(\frac{(1-\eta)(\theta-1)}{\theta}\left(\alpha-\left(\frac{1-\eta+\eta \theta}{\theta}\right) \frac{v_{\varepsilon}}{2}\right)\right)
\end{aligned}
$$


where the last step exploits the fact that $\varepsilon$ is log-normal. Combining this last equation with (16) yields an expression for $\mu$. Substituting this expression into (18) to solve for consumption, and then using (15) to solve for hours yields the candidate equilibrium allocations, as functions of primitive parameters, reported in Section 4.1 in the main text.

The last step of the proof requires verifying the no-trade guess. At the candidate allocations $c(\alpha, \varepsilon)$ and $h(\alpha, \varepsilon)$, the agent's Euler equation

$$
u_{c}(c(\alpha, \varepsilon), h(\alpha, \varepsilon))=\beta R \int_{E} u_{c}\left(c\left(\alpha, \varepsilon^{\prime}\right), h\left(\alpha, \varepsilon^{\prime}\right)\right) d \Phi_{v_{\varepsilon}}(\varepsilon)
$$

yields an interest rate of $R=1 / \beta$ which supports the equilibrium without trade across $\alpha$-islands, since it is independent of $\alpha$.

Finally, we guess and will verify that net savings are zero for every agent. Under this conjecture, from the budget constraint

$$
\begin{aligned}
b\left(\varepsilon^{\prime} ;(\alpha, \varepsilon)\right) & =c\left(\alpha, \varepsilon^{\prime}\right)-w\left(\alpha, \varepsilon^{\prime}\right) h\left(\alpha, \varepsilon^{\prime}\right) \\
& =\exp \left(\alpha+(1-\lambda) \varepsilon^{\prime}+\lambda(1-\lambda) \frac{v_{\varepsilon}}{2}\right)-\exp \left(\alpha+\varepsilon^{\prime}\right) .
\end{aligned}
$$

The first-order condition for the purchase of Arrow securities paying one unit of consumption in the event that an individual with state $(\alpha, \varepsilon)$ receives shock $\varepsilon^{\prime} \in \mathcal{E}$ next period is

$$
u_{c}(c(\alpha, \varepsilon), h(\alpha, \varepsilon)) p(\mathcal{E})=\beta \int_{\mathcal{E}} u_{c}\left(c\left(\alpha, \varepsilon^{\prime}\right), h\left(\alpha, \varepsilon^{\prime}\right)\right) d \Phi_{v_{\varepsilon}}(\varepsilon)
$$

which yields $p(\mathcal{E})=\beta \int_{\mathcal{E}} d \Phi_{v_{\varepsilon}}(\varepsilon)$, i.e., asset prices are discounted probabilities. It is then straightforward to verify that the cost of the entire portfolio of Arrow securities is zero:

$$
\int_{E} b\left(\varepsilon^{\prime} ;(\alpha, \varepsilon)\right) p\left(\varepsilon^{\prime}\right) d \varepsilon^{\prime}=\beta \int_{E} b\left(\varepsilon^{\prime} ;(\alpha, \varepsilon)\right) d \Phi_{v_{\varepsilon}}\left(\varepsilon^{\prime}\right)=0 .
$$

\section{Appendix B: Proof of Proposition 1}

Start by computing unconditional expected utility

$$
\begin{aligned}
\mathcal{W} & =\mathbb{E}\left[\frac{\left(c(\alpha, \varepsilon)^{\eta}(1-h(\alpha, \varepsilon))^{1-\eta}\right)^{1-\theta}}{1-\theta}\right]= \\
& =\frac{\left(\frac{1-\eta}{\eta}\right)^{(1-\eta)(1-\theta)}}{1-\theta} \mathbb{E}\left[\exp (-(1-\eta)(1-\theta)(\alpha+\varepsilon)) c(\alpha, \varepsilon)^{(1-\theta)}\right]
\end{aligned}
$$


where the second equality follows from the intratemporal first-order condition (15). Substituting for the equilibrium expression for $c(\alpha, \varepsilon)$ in $(11)$, expected utility becomes:

$$
\begin{aligned}
\mathcal{W} & =\kappa \mathbb{E} \exp \left(\eta(1-\theta) \alpha-(1-\eta)(1-\theta) \varepsilon+\frac{(1-\theta)(1-\eta)(\theta-1)}{\theta}\left(\varepsilon+\frac{1-\eta+\eta \theta}{\theta} \frac{v_{\varepsilon}}{2}\right)\right) \\
& =\kappa \exp \left(\frac{(1-\eta+\eta \theta)(1-\eta)(1-\theta)}{\theta} \frac{v_{\varepsilon}}{2}-(1-\eta+\eta \theta) \eta(1-\theta) \frac{v_{\alpha}}{2}\right)
\end{aligned}
$$

where $\kappa \equiv((1-\eta) / \eta)^{(1-\eta)(1-\theta)} \eta^{1-\theta} /(1-\theta)$, and where the second equation follows from $\alpha$ and $\varepsilon$ being log-normal. Recall that $\omega$ is defined by equation (4). Substituting (19) into (4) and collecting terms yields an exact expression for $\omega$

$$
1+\omega=\exp \left(\frac{1-\eta}{\eta}\left(\frac{1-\eta+\eta \theta}{\theta}\right) \frac{\Delta v_{\varepsilon}}{2}-(1-\eta+\eta \theta) \frac{\Delta v_{\alpha}}{2}\right)=\exp \left(\bar{\phi} \frac{\Delta v_{\varepsilon}}{2}-\bar{\gamma} \frac{\Delta v_{\alpha}}{2}\right) .
$$

Taking logarithms on both sides and using a log-approximation of the type $\ln (1+\omega) \simeq \omega$ for the left-hand side yields the expression stated in Proposition 1.

We now show how to decompose $\omega$ into a level effect and a volatility effect. From equation (5), the level effect of changing variances from $\left(v_{\alpha}, v_{\varepsilon}\right)$ to $\left(\hat{v}_{\alpha}, \hat{v}_{\varepsilon}\right)$ is given by

$$
\frac{\left(\left(1+\omega^{l e v}\right)^{\eta} C^{\eta}(1-H)^{1-\eta}\right)^{1-\theta}}{1-\theta}=\frac{\left(\widehat{C}^{\eta}(1-\widehat{H})^{1-\eta}\right)^{1-\theta}}{1-\theta}
$$

where aggregate consumption and leisure are given by

$$
\begin{aligned}
C & =\mathbb{E}[c(\alpha, \varepsilon)]=\eta, \\
1-H & =\mathbb{E}[1-h(\alpha, \varepsilon)]=(1-\eta) \exp \left(\lambda v_{\varepsilon}\right) .
\end{aligned}
$$

Since $C$ is invariant to wage dispersion, it follows that $\left(1+\omega^{l e v}\right)^{\eta}(1-H)^{1-\eta}=(1-\widehat{H})^{1-\eta}$, which yields the level effect of Proposition 1. Flodén (2001) shows that if $u(\cdot)$ is such that $u(x c, h)=g(x) u(c, h)$, then

$$
1+\omega=\left(1+\omega^{l e v}\right)\left(1+\omega^{v o l}\right) \Rightarrow \omega \simeq \omega^{l e v}+\omega^{v o l},
$$

up to second-order terms. Since Cobb-Douglas preferences satisfy this homogeneity property, equation (21) defines $\omega^{v o l}$ residually, given $\omega^{\text {lev }}$.

\section{Appendix C: Derivation of Equilibrium Allocations (Separable Utility)}

When preferences are separable between consumption and hours, the first-order conditions for the planner problem (14) imply

$$
\begin{aligned}
c(\alpha, \varepsilon) & =\mu^{-1 / \gamma}, \\
h(\alpha, \varepsilon) & =c(\alpha, \varepsilon)^{-\gamma / \sigma} \exp \left(\frac{\alpha+\varepsilon}{\sigma}\right) .
\end{aligned}
$$


Equation (22) implies that all agents on an $\alpha$-island get the same consumption (since preferences are separable). Using the planner's resource constraint (14), one can solve for the multiplier $\mu$ :

$$
\mu=\exp \left(-\gamma\left(\alpha+\frac{v_{\varepsilon}}{2 \sigma}\right) \frac{1+\sigma}{\sigma+\gamma}\right) .
$$

Substituting this expression into equations (22) yields efficient allocations only as a function of the primitive parameters, as described in Section 5.1 in the main text. We then can verify the no-trade guess exactly as done for the Cobb-Douglas case.

\section{Appendix D: Proof of Proposition 1A}

As in the proof of the Cobb-Douglas case (Appendix B), we start by computing expected welfare. When preferences are separable between consumption and hours worked, unconditional expected period utility is given by

$$
\mathcal{W}=\mathbb{E}\left[\frac{c(\alpha, \varepsilon)^{1-\gamma}}{1-\gamma}-\frac{h(\alpha, \varepsilon)^{1+\sigma}}{1+\sigma}\right]
$$

Using the equilibrium expressions for $c(\alpha, \varepsilon)$ and $h(\alpha, \varepsilon)$ in the above equation yields

$$
\begin{aligned}
\mathcal{W}= & \frac{1}{1-\gamma} \exp \left(\frac{(1+\sigma)(1-\gamma)}{\gamma+\sigma} \frac{v_{\varepsilon}}{2 \sigma}\right) \mathbb{E}\left[\exp \left(\frac{(1+\sigma)(1-\gamma)}{\gamma+\sigma} \alpha\right)\right]- \\
& \frac{1}{1+\sigma} \exp \left(\frac{-(1+\sigma)^{2}}{\gamma+\sigma} \frac{\gamma v_{\varepsilon}}{2 \sigma^{2}}\right) \mathbb{E}\left[\exp \left(\frac{(1+\sigma)(1-\gamma)}{\gamma+\sigma} \alpha\right) \exp \left(\frac{1+\sigma}{\sigma} \varepsilon\right)\right] .
\end{aligned}
$$

Since $\alpha$ and $\varepsilon$ are normally distributed, the terms inside the expectation signs are lognormally distributed too, and one can easily compute that

$$
\begin{aligned}
\mathbb{E}\left[\exp \left(\frac{(1+\sigma)(1-\gamma)}{\gamma+\sigma} \alpha\right)\right] & =\exp \left(\kappa(\kappa-1) \frac{v_{\alpha}}{2}\right) \\
\mathbb{E}\left[\exp \left(\frac{(1+\sigma)(1-\gamma)}{\gamma+\sigma} \alpha\right) \exp \left(\frac{1+\sigma}{\sigma} \varepsilon\right)\right] & =\exp \left(\kappa(\kappa-1) \frac{v_{\alpha}}{2}\right) \exp \left(\frac{1+\sigma}{\sigma^{2}} \frac{v_{\varepsilon}}{2}\right),
\end{aligned}
$$

where $\kappa \equiv \frac{(1+\sigma)(1-\gamma)}{\gamma+\sigma}$.

Collecting terms, the expression for expected lifetime utility reduces to

$$
\begin{aligned}
\mathcal{W} & =\exp \left(\kappa(\kappa-1) \frac{v_{\alpha}}{2}\right) \exp \left(\kappa \frac{v_{\varepsilon}}{2 \sigma}\right)\left(\frac{1}{1-\gamma}-\frac{1}{1+\sigma}\right) \\
& =\exp \left(\kappa(\kappa-1) \frac{v_{\alpha}}{2}\right) \exp \left(\kappa \frac{v_{\varepsilon}}{2 \sigma}\right) \frac{1}{\kappa}
\end{aligned}
$$


Using this expression for expected lifetime utility together with the definition of $\omega$ in equation (4), we obtain that $\omega$ is implicitly defined by

$$
\left(\frac{(1+\omega)^{1-\gamma}}{1-\gamma}-\frac{1}{1+\sigma}\right)=\exp \left(\kappa(\kappa-1) \frac{\Delta v_{\alpha}}{2}+\kappa \frac{\Delta v_{\varepsilon}}{2 \sigma}\right) \frac{1}{\kappa}
$$

or

$$
1+\omega=\left[\frac{1-\gamma}{1+\sigma}+\frac{\gamma+\sigma}{1+\sigma} \exp \left(\kappa(\kappa-1) \frac{\Delta v_{\alpha}}{2}+\kappa \frac{\Delta v_{\varepsilon}}{2 \sigma}\right)\right]^{\frac{1}{1-\gamma}}
$$

This welfare expression is exact, but somewhat involved. However, $\omega$ can be very closely approximated by a much simpler expression. In particular, we use a log-approximation of the type $\ln (1+x) \simeq x$ on the left-hand side of the equation, and the approximation $\exp (x) \simeq 1+x$ on the right-hand side, which gives

$$
\begin{aligned}
\omega & \simeq \frac{1}{1-\gamma} \ln \left[\frac{1-\gamma}{1+\sigma}+\frac{\gamma+\sigma}{1+\sigma}\left(1+\kappa(\kappa-1) \frac{\Delta v_{\alpha}}{2}+\kappa \frac{\Delta v_{\varepsilon}}{2 \sigma}\right)\right] \\
& =\frac{1}{1-\gamma} \ln \left[1+\frac{\gamma+\sigma}{1+\sigma}\left(\kappa \frac{\Delta v_{\varepsilon}}{2 \sigma}+\kappa(\kappa-1) \frac{\Delta v_{\alpha}}{2}\right)\right] \\
& \simeq \frac{1}{\kappa}\left(\kappa \frac{\Delta v_{\varepsilon}}{2 \sigma}+\kappa(\kappa-1) \frac{\Delta v_{\alpha}}{2}\right) \\
& =\frac{\Delta v_{\varepsilon}}{2 \sigma}+(\kappa-1) \frac{\Delta v_{\alpha}}{2} \\
& =\frac{1}{\sigma} \frac{\Delta v_{\varepsilon}}{2}+\left[\frac{(1-\gamma)-\gamma(1+\sigma)}{\gamma+\sigma}\right] \frac{\Delta v_{\alpha}}{2},
\end{aligned}
$$

where the last expression is the one we report in the text in Proposition 1a.

We now show how to decompose $\omega$ into a level effect and a volatility effect. Aggregate consumption and leisure allocations are given by:

$$
\begin{aligned}
& C=\mathbb{E}[c(\alpha, \varepsilon)]=\exp \left(\left(\frac{1+\sigma}{\gamma+\sigma}\right) \frac{v_{\varepsilon}}{2 \sigma}\right) \exp \left(\frac{(1+\sigma)(1-\gamma)}{(\gamma+\sigma)^{2}} \frac{v_{\alpha}}{2}\right), \\
& H=\mathbb{E}[h(\alpha, \varepsilon)]=\exp \left(\frac{1-2 \gamma-\sigma}{(\gamma+\sigma) \sigma} \frac{v_{\varepsilon}}{2}\right) \exp \left(\frac{(1-\gamma)(1-2 \gamma-\sigma)}{(\gamma+\sigma)^{2}} \frac{v_{\alpha}}{2}\right) .
\end{aligned}
$$

With these expressions in hand, we compute the level affect associated with an increase in the variances of the two components of the wage from $\left(v_{\alpha}, v_{\varepsilon}\right)$ to $\left(\widehat{v}_{\alpha}, \widehat{v}_{\varepsilon}\right)$ by applying the definition in equation (5) to the separable preference specification:

$$
\frac{\left(1+\omega^{l e v}\right)^{1-\gamma} C^{1-\gamma}}{1-\gamma}-\frac{H^{1+\sigma}}{1+\sigma}=\frac{\widehat{C}^{1-\gamma}}{1-\gamma}-\frac{\widehat{H}^{1+\sigma}}{1+\sigma},
$$


where $\widehat{C}$ and $\widehat{H}$ denote average consumption and hours worked in the economy with the more volatile wage process. Substituting in the expressions for aggregate variables and collecting terms gives

$$
\begin{aligned}
\left(1+\omega^{\text {lev }}\right)^{1-\gamma}= & \frac{1-\gamma}{1+\sigma} \exp \left(-\frac{1+\sigma}{\sigma} \frac{v_{\varepsilon}}{2}\right) \exp \left(-\kappa \frac{v_{\alpha}}{2}\right) \\
& -\frac{1-\gamma}{1+\sigma} \exp \left(\frac{\kappa}{\sigma} \frac{\Delta v_{\varepsilon}}{2}-\frac{1+\sigma}{\sigma} \frac{\widehat{v}_{\varepsilon}}{2}\right) \exp \left(\left(\frac{1-\gamma}{\gamma+\sigma} \kappa \frac{\Delta v_{\alpha}}{2}-\kappa \frac{\widehat{v}_{\alpha}}{2}\right)\right) \\
& +\exp \left(\kappa \frac{\Delta v_{\varepsilon}}{2 \sigma}\right) \exp \left(\frac{1-\gamma}{\gamma+\sigma} \kappa \frac{\Delta v_{\alpha}}{2}\right) .
\end{aligned}
$$

Applying the approximation $\exp (x) \simeq 1+x$ to the righ-hand side of this expression and collecting terms gives

$$
\frac{\left(1+\omega^{l e v}\right)^{1-\gamma}}{1-\gamma} \simeq \frac{1}{1-\gamma}+\frac{1}{\sigma} \Delta v_{\varepsilon}+\frac{1-\gamma}{\gamma+\sigma} \Delta v_{\alpha}
$$

Multiplying both sides by $(1-\gamma)$, and taking logs,

$$
(1-\gamma) \ln \left(1+\omega^{l e v}\right) \simeq \ln \left(1+(1-\gamma)\left[\frac{1}{\sigma} \Delta v_{\varepsilon}+\frac{1-\gamma}{(\gamma+\sigma)} \Delta v_{\alpha}\right]\right)
$$

Using the approximation $\ln (1+x) \simeq x$ on both sides of this expression gives

$$
\omega^{l e v} \simeq-\frac{\gamma-1}{\gamma+\sigma} \Delta v_{\alpha}+\frac{1}{\sigma} \Delta v_{\varepsilon}
$$

which is the expression reported in Proposition 1a.

We now compute the volatility component of the welfare effect. The first step is to calculate a certainty equivalent value for consumption $c(H)$, such that the utility associated with consuming $c(H)$ and working $H$ hours is equal to expected equilibrium lifetime utility, i.e.

$$
u(c(H), H)=\iint_{A} \int_{E} u(c(\alpha, \varepsilon), h(\alpha, \varepsilon)) d \Phi_{v_{\varepsilon}}(\varepsilon) d \Phi_{v_{\alpha}}(\alpha) .
$$

Given the separable specification for preferences, and equations (23) and (25) for expected utility and aggregate hours, the expression for certainty equivalent consumption can be rewritten in terms of the pair $\left(v_{\alpha}, v_{\varepsilon}\right)$ and preference parameters:

$$
\begin{aligned}
c(H)^{1-\gamma}= & \frac{1}{1+\sigma}(\gamma+\sigma) \exp \left(\frac{(1+\sigma)(1-\gamma)}{\gamma+\sigma}\left(\frac{1-2 \gamma-\gamma \sigma}{\gamma+\sigma} \frac{v_{\alpha}}{2}+\frac{1}{\sigma} \frac{v_{\varepsilon}}{2}\right)\right)+ \\
& \frac{1}{1+\sigma}(1-\gamma) \exp \left(\frac{(1+\sigma)(1-2 \gamma-\sigma)}{\gamma+\sigma}\left(\frac{1-\gamma}{\gamma+\sigma} \frac{v_{\alpha}}{2}+\frac{1}{\sigma} \frac{v_{\varepsilon}}{2}\right)\right) .
\end{aligned}
$$


Applying the approximation $\exp (x) \simeq 1+x$ and collecting terms gives

$$
\begin{aligned}
c(H)^{1-\gamma} \simeq & \frac{(1-\gamma)[(1-2 \gamma-\gamma \sigma)(\gamma+\sigma)+(1-\gamma)(1-2 \gamma-\sigma)]}{(\gamma+\sigma)^{2}} \frac{v_{\alpha}}{2}+ \\
& +\frac{1}{\sigma} \frac{(1-\gamma)^{2}}{\gamma+\sigma} \frac{v_{\varepsilon}}{2}+1 .
\end{aligned}
$$

Using the approximation $1+x \simeq \exp (x)$ and raising both sides of the equation to the power $\frac{1}{1-\gamma}$ gives

$$
c(H) \simeq \exp \left(\frac{(1-2 \gamma-\gamma \sigma)(\gamma+\sigma)+(1-\gamma)(1-2 \gamma-\sigma)}{(\gamma+\sigma)^{2}} \frac{v_{\alpha}}{2}+\frac{1}{\sigma}\left(\frac{1-\gamma}{\gamma+\sigma}\right) \frac{v_{\varepsilon}}{2}\right) .
$$

Applying the definition in equation (6), the cost of uncertainty $p$ is the solution to

$$
u((1-p) C, H)=u(c(H), H)
$$

which, given separable preferences, implies $1-p=c(H) / C$. Substituting in equations $(24)$ and (26) gives

$$
1-p \simeq \exp \left(-\frac{1+\sigma \gamma}{\gamma+\sigma} \frac{v_{\alpha}}{2}-\frac{1}{\sigma} \frac{v_{\varepsilon}}{2}\right)=\exp \left(-\frac{1-\gamma}{\gamma+\sigma} \frac{v_{\alpha}}{2}-\gamma\left(\frac{1+\sigma}{\gamma+\sigma}\right) \frac{v_{\alpha}}{2}-\frac{1}{\sigma} \frac{v_{\varepsilon}}{2}\right)
$$

Using the definition for the cost of volatility in equation (7) gives

$$
\begin{aligned}
1+\omega^{v o l} & =\frac{1-\widehat{p}}{1-p} \simeq \exp \left(-\frac{1-\gamma}{\gamma+\sigma} \frac{\Delta v_{\alpha}}{2}-\gamma\left(\frac{1+\sigma}{\gamma+\sigma}\right) \frac{\Delta v_{\alpha}}{2}-\frac{1}{\sigma} \frac{\Delta v_{\varepsilon}}{2}\right) \\
& \simeq 1+\left[\frac{\gamma-1}{\gamma+\sigma}-\gamma\left(\frac{1+\sigma}{\gamma+\sigma}\right)\right] \frac{\Delta v_{\alpha}}{2}-\frac{1}{\sigma} \frac{\Delta v_{\varepsilon}}{2}
\end{aligned}
$$

which implies the expression for $\omega^{v o l}$ reported in Proposition 1a.

\section{Appendix E: Proof of Proposition 2}

Cobb-Douglas utility: From the log-normality of $c$ and $1-h$ (Assumption A1), expected utility is given by

$$
\begin{aligned}
& \mathbb{E}\left[\frac{1}{1-\theta}\left(c^{\eta}(1-h)^{1-\eta}\right)^{1-\theta}\right]=\frac{1}{1-\theta} \mathbb{E}[\exp ((1-\theta) \eta \log c+(1-\theta)(1-\eta) \log (1-h))] \\
& =\frac{1}{1-\theta} \exp \left((1-\theta) \eta \mu_{c}+(1-\theta)(1-\eta) \mu_{l}+\frac{(1-\theta)^{2}\left[\eta^{2} v_{c}+(1-\eta)^{2} v_{l}+2 \eta(1-\eta) v_{c l}\right]}{2}\right)
\end{aligned}
$$

where we have used the notation $\mathbb{E}[\log x] \equiv \mu_{x}, \operatorname{var}(\log x) \equiv v_{x}$, and $\operatorname{cov}(\log x, \log y) \equiv v_{x y}$ for any variables $x$ and $y$. The welfare effect $\omega$ of changing to a new distribution of allocations (denoted with hats) is defined as

$$
\mathbb{E}[u(\hat{c}, \hat{h})]=\mathbb{E}[u((1+\omega) c, h)] .
$$


Substituting (27) into (28) we obtain

$$
\begin{aligned}
& \eta(1-\theta) \log (1+\omega)+(1-\theta) \eta \mu_{c}+(1-\theta)(1-\eta) \mu_{l}+\frac{(1-\theta)^{2}\left[\eta^{2} v_{c}+(1-\eta)^{2} v_{l}+2 \eta(1-\eta) v_{c l}\right]}{2} \\
= & (1-\theta) \eta \hat{\mu}_{c}+(1-\theta)(1-\eta) \hat{\mu}_{l}+\frac{(1-\theta)^{2}\left[\eta^{2} \hat{v}_{c}+(1-\eta)^{2} \hat{v}_{l}+2 \eta(1-\eta) \hat{v}_{c l}\right]}{2} .
\end{aligned}
$$

Rearranging terms, using the fact that $\log (1+\omega) \simeq \omega$ for $\omega$ small, and noting that $C \equiv$ $\mathbb{E}(c)=\exp \left(\mu_{c}+v_{c} / 2\right)$, and $1-H \equiv \mathbb{E}(1-h)=\exp \left(\mu_{l}+v_{l} / 2\right)$ yields

$$
\begin{aligned}
\omega & \simeq \Delta \log C+\frac{1-\eta}{\eta} \Delta \log (1-H)-\frac{1-(1-\theta) \eta}{2} \Delta v_{c}-\frac{1-\eta}{2 \eta}[1-(1-\theta)(1-\eta)] \Delta v_{l} \\
& +(1-\theta)(1-\eta) \Delta v_{c l} \\
& =\Delta \log C+\frac{1-\eta}{\eta} \Delta \log (1-H)-\frac{1}{2} \bar{\gamma} \Delta v_{c}-\frac{1}{2}\left[\bar{\gamma}-1+\frac{\eta}{1-\eta}\right]\left(\frac{1-\eta}{\eta}\right)^{2} \Delta v_{l} \\
& +(1-\bar{\gamma})\left(\frac{1-\eta}{\eta}\right) \Delta v_{c l}
\end{aligned}
$$

By Assumption A2, the individual intratemporal first-order condition is satisfied:

$$
(1-\eta) c=\eta w(1-h)
$$

Taking expectations of (30), and using $W \equiv \mathbb{E}(w)=1$ by Assumption A1, as well as $\mathbb{E}(w h)=C$ by Assumption A2, yields $C=\eta$ (and therefore, $\Delta \log C=0$ ). At the same time, by Assumption A2 and by the log-normality of the allocations, we also have that

$$
C=\mathbb{E}(w h)=W-\mathbb{E}[w(1-h)]=1-\exp \left(\mu_{l}+\frac{v_{l}}{2}+v_{w l}\right)=1-(1-H) \exp \left(v_{w l}\right)
$$

where we have used the fact that $W=1$. Setting $C=\eta$,

$$
\Delta v_{w l}=-\Delta \log (1-H) \text {. }
$$

Now, note that, for small deviations of $h$ from its mean, we can write

$$
\begin{aligned}
\log (1-h) & =\log (1-H)+\log \frac{1-h}{1-H} \simeq \log (1-H)+\frac{1-h}{1-H}-1 \\
& =\log (1-H)-\frac{H}{1-H}\left(\frac{h}{H}-1\right) \simeq \log (1-H)-\frac{H}{1-H} \log \left(\frac{h}{H}\right) \\
& \simeq \log (1-H)+\frac{H}{1-H} \log H-\frac{\eta}{1-\eta} \log h,
\end{aligned}
$$

where the last approximation uses $H \simeq \eta$, which is true for $v_{w l}$ small (see equation (31)). Exploiting this relationship between $\log (1-h)$ and $\log h$, it is easy to see that

$$
v_{h} \simeq\left(\frac{1-\eta}{\eta}\right)^{2} v_{l}, \quad v_{w h} \simeq-\frac{1-\eta}{\eta} v_{w l}, \quad \text { and } \quad v_{c h} \simeq-\frac{1-\eta}{\eta} v_{c l}
$$


Substituting (32) and (33) into equation (29) yields immediately the representation for $\omega$ in Proposition 2 for the Cobb-Douglas case.

It remains to show how to decompose $\omega$ into a level effect and a volatility effect. The definition of level effect in (20) for the Cobb-Douglas case implies, after rearranging terms,

$$
\log \left(1+\omega^{l e v}\right) \simeq \omega^{l e v}=\Delta \log C+\frac{1-\eta}{\eta} \Delta \log (1-H)
$$

Since $\Delta \log C=0$, equations (32) and (33) imply that $\omega^{\text {lev }} \simeq v_{w h}$. Moreover, equation (34) and

$$
\frac{1-\eta}{\eta} \Delta \log (1-H) \simeq\left(\frac{1-\eta}{\eta}\right) \frac{\Delta(1-H)}{1-H} \simeq \frac{-\Delta H}{H} \simeq-\Delta \log H
$$

where we have used $H \simeq \eta$, jointly imply that $\omega^{l e v} \simeq \Delta \log (C / H)$. As argued in the proof of Proposition 1, the volatility effect is defined residually.

Separable utility: In this case, expected utility is given by

$$
\begin{aligned}
\mathbb{E}[u(c, h)] & =\mathbb{E}\left[\frac{c^{1-\gamma}}{1-\gamma}-\psi \frac{h^{1+\sigma}}{1+\sigma}\right] \\
& =\frac{1}{1-\gamma} \mathbb{E}[\exp ((1-\gamma) \log c)]-\frac{\psi}{1+\sigma} \mathbb{E}[\exp ((1+\sigma) \log h)] \\
& =\frac{1}{1-\gamma} \exp \left((1-\gamma) \mu_{c}+(1-\gamma)^{2} \frac{v_{c}}{2}\right)-\frac{\psi}{1+\sigma} \exp \left((1+\sigma) \mu_{h}+(1+\sigma)^{2} \frac{v_{h}}{2}\right) .
\end{aligned}
$$

Using (35) into the definition of the welfare effect $\omega$ of equation (4), and rearranging terms, yields

$$
\begin{aligned}
& \frac{1}{1-\gamma}\left[\exp \left((1-\gamma) \hat{\mu}_{c}+(1-\gamma)^{2} \frac{\hat{v}_{c}}{2}\right)-(1+\omega)^{1-\gamma} \exp \left((1-\gamma) \mu_{c}+(1-\gamma)^{2} \frac{v_{c}}{2}\right)\right] \\
= & \frac{\psi}{1+\sigma}\left[\exp \left((1+\sigma) \hat{\mu}_{h}+(1+\sigma)^{2} \frac{\hat{v}_{h}}{2}\right)-\exp \left((1+\sigma) \mu_{h}+(1+\sigma)^{2} \frac{v_{h}}{2}\right)\right] .
\end{aligned}
$$

Using the expressions for average allocations $C$ and $H$ under log-normality gives

$$
\begin{gathered}
\frac{1}{1-\gamma}\left[\exp \left((1-\gamma) \Delta \log C-\gamma(1-\gamma) \frac{\hat{v}_{c}}{2}\right)-\exp \left((1-\gamma) \log (1+\omega)-\gamma(1-\gamma) \frac{v_{c}}{2}\right)\right] \\
=\frac{\psi H^{1+\sigma}}{C^{1-\gamma}} \frac{1}{1+\sigma}\left[\exp \left((1+\sigma) \Delta \log H+\sigma(\sigma+1) \frac{\hat{v}_{h}}{2}\right)-\exp \left(\sigma(\sigma+1) \frac{v_{h}}{2}\right)\right] .
\end{gathered}
$$

Consider now the term

$$
\frac{\psi H^{1+\sigma}}{C^{1-\gamma}}=\psi \frac{\exp \left((1+\sigma) \mu_{h}+(1+\sigma) \frac{v_{h}}{2}\right)}{\exp \left((1-\gamma) \mu_{c}+(1-\gamma) \frac{v_{c}}{2}\right)} .
$$


The intratemporal first-order condition (satisfied by Assumption A2), can be expressed as

$$
\log \psi+\sigma \log h=\log w-\gamma \log c
$$

Taking expectations, we obtain

$$
\psi=\exp \left(-\frac{v_{w}}{2}-\gamma \mu_{c}-\sigma \mu_{h}\right)
$$

Moreover, recall that, from Assumption A2,

$$
C=\mathbb{E}(w h) \Rightarrow \exp \left(\mu_{h}+\frac{v_{h}}{2}-\mu_{c}-\frac{v_{c}}{2}+v_{w h}\right)=1
$$

Using (38) and (39) into (37), and simplyfing, yields

$$
\frac{\psi H^{1+\sigma}}{C^{1-\gamma}}=\exp \left(\sigma \frac{v_{h}}{2}+\gamma \frac{v_{c}}{2}-\frac{v_{w}}{2}-v_{w h}\right) \simeq 1
$$

where the approximation holds when cross-sectional dispersion is small. ${ }^{30}$

Using this result into (36), and exploiting approximations of the type $\log (1+x) \simeq x$ and $\exp (x) \simeq 1+x$ for $x \simeq 0$, we arrive at

$$
\begin{aligned}
& \frac{1}{1-\gamma}\left[\left((1-\gamma) \Delta \log C-\gamma(1-\gamma) \frac{\hat{v}_{c}}{2}+1\right)-\left((1-\gamma) \omega-\gamma(1-\gamma) \frac{v_{c}}{2}+1\right)\right] \\
\simeq & \frac{1}{1+\sigma}\left[(1+\sigma) \Delta \log H+\sigma(\sigma+1) \frac{\hat{v}_{h}}{2}+1-\left(\sigma(\sigma+1) \frac{v_{h}}{2}+1\right)\right],
\end{aligned}
$$

which implies

$$
\omega \simeq \Delta \log C-\Delta \log H-\frac{\gamma}{2} \Delta v_{c}-\frac{\sigma}{2} \Delta v_{h}
$$

From (39), we have that $C / H=\exp \left(v_{w h}\right)$. Taking logs and first differences,

$$
\omega^{l e v}=\Delta \log C-\Delta \log H=\Delta v_{w h} .
$$

Substituting this expression into (41) yields the representation of Proposition 2 for separable utility.

\footnotetext{
${ }^{30}$ For example, consider the parameterization of Section 7.1 , where $\gamma=\sigma=2$, and the empirical values for the variances and covariances needed to compute expression (40) are: $v_{h}=0.092, v_{c}=0.25, v_{w}=0.35$, and $v_{w h}=-0.006$ (see Table A). This parameterization gives $\exp \left(\sigma \frac{v_{h}}{2}+\gamma \frac{v_{c}}{2}-\frac{v_{w}}{2}-v_{w h}\right) \simeq 1.19$.
} 


\section{References}

[1] Acemoglu, D. (2002); "Technical Change, Inequality and the Labor Market," Journal of Economic Literature 40 (1), 7-72.

[2] Aghion, P. (2002); "Schumpeterian Growth Theory and the Dynamics of Income Inequality," Econometrica 70 (3), 855-82.

[3] Aiyagari, R. (1994); "Uninsured Idiosyncratic Risk and Aggregate Savings," Quarterly Journal of Economics 109 (3), 659-684.

[4] Altonji, J.,Hayashi F., Kotlikoff L. (1992); "Is the Extended Family Altruistically Linked? Direct Tests Using Micro Data," American Economic Review, vol. 82(5), 1177-1198.

[5] Attanasio, O. (1999); "Consumption," Handbook of Macroeconomics Volume 1B, Chapter 11, Amsterdam: Elsevier Science

[6] Attanasio, O., Davis S. (1996); "Relative Wage Movements and the Distribution of Consumption," Journal of Political Economy 104(6), 1227-62.

[7] Attanasio, O., Battistin E., Ichimura H., (2004); "What Really Happened to Consumption Inequality in the US?," NBER Working Paper No. 10338.

[8] Benabou, R. (2002); "Tax and Education Policy in a Heterogeneous Agent Economy: What Levels of Redistribution Maximizes Growth and Efficiency?," Econometrica, 70, 481-517.

[9] Bewley, T. (1986): "Stationary Monetary Equilibrium with a Continuum of Independently Fluctuating Consumers," in W. Hildenbrand and A. Mas-Colell, eds., Contributions to Mathematical Economics: In Honor of Gerard Debreu, New York: North Holland, 79-102.

[10] Blundell, R., MaCurdy, T. (1999), "Labor Supply: A Review of Alternative Approaches," in A. Ashenfelter and D. Card, eds, Handbook of Labor Economics, vol. 3, Amsterdam: Elsevier Science.

[11] Blundell, R., Pistaferri L., Preston I. (2005); "Consumption Inequality and Partial Insurance," IFS Working Paper, W04/28.

[12] Blundell, R., Preston I. (1998); "Consumption Inequality and Income Uncertainty," Quarterly Journal of Economics 113 (2), 603-640.

[13] Browning, M., Hansen L.P., Heckman J. (1999), "Micro Data and General Equilibrium Models," Handbook of Macroeconomics, Volume 1A, Amsterdam: Elsevier Science.

[14] Browning, M., Meghir C. (1991); "The Effects of Male and Female Labor Supply on Commodity Demands," Econometrica, vol. 59(4), 925-51.

[15] Carroll, C. (1997); "Buffer-Stock Saving and the Life Cycle/Permanent Income Hypothesis," Quarterly Journal of Economics, 112(1), 1-56.

[16] Cho, J.O., Cooley T.F. (2001); "Business Cycle Uncertainty and Economic Welfare," mimeo Stern School of Business, New York University. 
[17] Cochrane, J. (1991); "A Simple Test of Consumption Insurance," Journal of Political Economy, vol. 99(5), 957-76.

[18] Cooley, T. (1995); Frontiers of Business Cycle Research, Princeton University Press.

[19] Cordoba J., Verdier G. (2007); "Lucas vs. Lucas: On Inequality and Growth", IMF Working Paper No. 07/17.

[20] Deaton, A. (1991); "Saving and Liquidity Constraints," Econometrica, vol. 59(5), 1221-48.

[21] Domeij, D., Flodén M. (2006); "The Labor-Supply Elasticity and Borrowing Constraints: Why Estimates are Biased," Review of Economic Dynamics 9, 242-262.

[22] Eckstein, Z., Nagypal E. (2004); "The Evolution of U.S. Earnings Inequality: 1961-2002," Federal Reserve Bank of Minneapolis Quarterly Review 28(2), 10-29.

[23] Flodén, M. (2001); "The Effectiveness of Government Debt and Transfers as Insurance," Journal of Monetary Economics, vol. 48(1), 81-108.

[24] Gottschalk, P., Moffitt R. (1994); "The Growth of Earnings Instability in the U.S. Labor Market," Brookings Papers of Economic Activity 2, 217-272.

[25] Gomes, J., Greenwood J., Rebelo S. (2001); “Equilibrium Unemployment," Journal of Monetary Economics, vol. 48(1), 109-152.

[26] Guiso, L., Pistaferri, L., Schivardi F. (2005); "Insurance within the Firm," Journal of Political Economy, vol 113, 1054-1087.

[27] Heathcote, J., Storesletten K., Violante G.L. (2007a); "The Macroeconomic Implications of Rising Wage Inequality in the United States," CEPR Working Paper no. 4296.

[28] Heathcote, J., Storesletten K., Violante G.L. (2007b); "Consumption and Labor Supply with Partial Insurance: An Analytical Framework," mimeo, NYU.

[29] Heckman, J. (1974); "Life-Cycle Consumption and Labor Supply: An Explanation of the Relationship between Income and Consumption over the Life-Cycle," American Economic Review 64, 188-194.

[30] Hornstein A., Krusell P., Violante G.L. (2005); "The Effects of Technical Change on Labor Market Inequalities," in P. Aghion and S. Durlauf (eds.), Handbook of Economic Growth, Amsterdam: Elsevier Science, 1(B), 1275-1370.

[31] Huggett, M. (1993); "The Risk Free Rate in Heterogeneous-Agents Incomplete-Insurance Economies," Journal of Economic Dynamics and Control, 17, 953-969.

[32] Huggett, M., Parra J.C. (2006); "How well does the US Social Insurance System provide Social Insurance," mimeo, Georgetown University.

[33] Imrohoruglu, A. (1989); "Cost of Business Cycles with Indivisibilities and Liquidity Constraints," Journal of Political Economy, 97(6), 1364-1383.

[34] Katz, L. M., Autor D. (1999); "Changes in the Wage Structure and Earnings Inequality," in O. Ashenfelter and D. Card (eds.), Handbook of Labor Economics, Vol. 3, Amsterdam: Elsevier Science. 
[35] Krebs, T. (2003); "Growth and Welfare Effects of Business Cycles in Economies with Idiosyncratic Human Capital Risk", Review of Economic Dynamics, 6, 846-868.

[36] Krebs, T., Krishna P., Maloney W. (2005), "Trade Policy, Income Risk, and Welfare," NBER Working Paper No. 11255.

[37] Krueger, D., Perri F. (2003); "On the Welfare Consequences of the Increase in Inequality in the United States," in M. Gertler and K. Rogoff (eds.), NBER Macroeconomics Annual 2003, Cambridge, MA: MIT Press.

[38] Krueger, D., Perri F. (2006); "Does Income Inequality Lead to Consumption Inequality? Evidence and Theory," Review of Economic Studies, 73(1), 163-193.

[39] Krusell, P., Smith, A. Jr. (1999); "On the Welfare Effects of Eliminating Business Cycles," Review of Economic Dynamics, 2(1), 245-272.

[40] Kubler F., Schmedders K. (2001); "Incomplete Markets, Transitory Shocks, and Welfare," Review of Economic Dynamics, 4(4), 747-766.

[41] Levine D.K., Zame W.R. (2002); "Does Market Incompleteness Matter?," Econometrica 70(5), 1805-1839.

[42] Livshits, I., MacGee, J., Tertilt M. (2006); "Consumer Bankruptcy: A Fresh Start," American Economic Review, forthcoming.

[43] Low, H. (2005); "Self-Insurance in a Life-Cycle Model of Labor Supply and Savings," Review of Economic Dynamics, 8(4), 945-975.

[44] Lucas, R. E., Jr. (1987); Models of Business Cycle, Oxford: Basil Blackwell.

[45] Lucas, R. E., Jr. (2003); "Macroeconomic Priorities," American Economic Review, 93(1), $1-14$.

[46] Mas-Colell A., Whinston M.D., Green J.R. (1995); Microeconomic Theory, Oxford: Oxford University Press.

[47] Mortensen, D. (2003); Wage Dispersion: Why Are Similar Workers Paid Differently?, Cambridge: MIT Press.

[48] Phelan, C. (2006); "Opportunity and Social Mobility," Review of Economic Studies, 73(2), 487-505.

[49] Pijoan-Mas, J. (2005); "Precautionary Savings or Working Longer Hours?," CEPR Discussion Paper No. 5322.

[50] Rios-Rull, V. (1994); On the Quantitative Importance of Market Incompleteness," Journal of Monetary Economics, 34, 463-496.

[51] Sargent, T. (2001); Discussion of "Can Market and Voting Institutions Generate Optimal Intergenerational Risk Sharing", by A. Rangel and R. Zeckhauser, in J.Y. Campbell and M. Feldstein (eds.), Risk Aspects of Investment-Based Social Security Reform, Chicago: The University of Chicago Press.

[52] Shiller, R.J. (2003); The New Financial Order: Risk in the 21st Century. Princeton: Princeton University Press. 
[53] Slesnick D. (2001); Consumption and Social Welfare: Living Standards and their Distribution in the United States. Cambridge, UK: Cambridge University Press.

[54] Storesletten, K., Telmer C., Yaron A. (2001); " The welfare cost of business cycles revisited: Finite lives and cyclical variation in idiosyncratic risk," European Economic Review, 45(7), 1311-1339. 
Table A: Summary statistics from PSID data

\begin{tabular}{cccc}
\hline \hline Year & $\begin{array}{c}\text { Variance of } \\
\text { log-wages }\end{array}$ & $\begin{array}{c}\text { Variance of } \\
\text { log-hours }\end{array}$ & $\begin{array}{c}\text { Covariance } \\
\text { log-wages log-hours }\end{array}$ \\
\hline $\mathbf{1 9 6 7}$ & $\mathbf{0 . 2 5 4 9 6}$ & $\mathbf{0 . 0 8 0 6 4}$ & $\mathbf{- 0 . 0 2 4 7 3}$ \\
$\mathbf{1 9 6 8}$ & $\mathbf{0 . 2 4 7 5 6}$ & $\mathbf{0 . 0 8 3 6 2}$ & $\mathbf{- 0 . 0 2 1 8 4}$ \\
1969 & 0.25206 & 0.08225 & -0.02417 \\
1970 & 0.26076 & 0.09592 & -0.02128 \\
1971 & 0.25906 & 0.08718 & -0.03173 \\
1972 & 0.26850 & 0.09268 & -0.02474 \\
1973 & 0.26640 & 0.08595 & -0.02443 \\
1974 & 0.25705 & 0.09583 & -0.02027 \\
1975 & 0.26036 & 0.10521 & -0.02227 \\
1976 & 0.26632 & 0.09131 & -0.02326 \\
1977 & 0.24934 & 0.08500 & -0.01365 \\
1978 & 0.26696 & 0.08103 & -0.01856 \\
1979 & 0.25401 & 0.08318 & -0.01258 \\
1980 & 0.26865 & 0.08975 & -0.01631 \\
1981 & 0.27447 & 0.08906 & -0.00852 \\
1982 & 0.30802 & 0.10198 & -0.00863 \\
1983 & 0.30302 & 0.10537 & 0.00172 \\
1984 & 0.31745 & 0.09564 & -0.00824 \\
1985 & 0.34405 & 0.09292 & -0.00573 \\
1986 & 0.34248 & 0.09463 & -0.00550 \\
1987 & 0.33425 & 0.09132 & -0.00178 \\
1988 & 0.33973 & 0.09331 & -0.00476 \\
1989 & 0.33208 & 0.08535 & -0.00605 \\
1990 & 0.34373 & 0.09598 & 0.00102 \\
1991 & 0.34268 & 0.09764 & -0.00917 \\
1992 & 0.36225 & 0.09871 & -0.01445 \\
1993 & 0.35083 & 0.10329 & -0.01457 \\
1994 & 0.34625 & 0.09318 & -0.00285 \\
$\mathbf{1 9 9 5}$ & $\mathbf{0 . 3 4 6 7 9}$ & $\mathbf{0 . 0 9 2 3 8}$ & $\mathbf{- 0 . 0 0 5 1 1}$ \\
$\mathbf{1 9 9 6}$ & $\mathbf{0 . 3 4 4 3 0}$ & $\mathbf{0 . 0 9 0 6 6}$ & $\mathbf{- 0 . 0 0 7 2 6}$ \\
\hline & & & \\
\hline & & & \\
\hline
\end{tabular}

Note: years in bold (1967-1968 and 1995-1996) are those used to compute values in initial and final steady-state. See Section 7.1 for details on the sample selection. 
(A) Welfare effect from rising labor market risk $(\omega)$

$$
\left(\Delta v_{\alpha}=\Delta v_{\varepsilon}=0.05\right)
$$

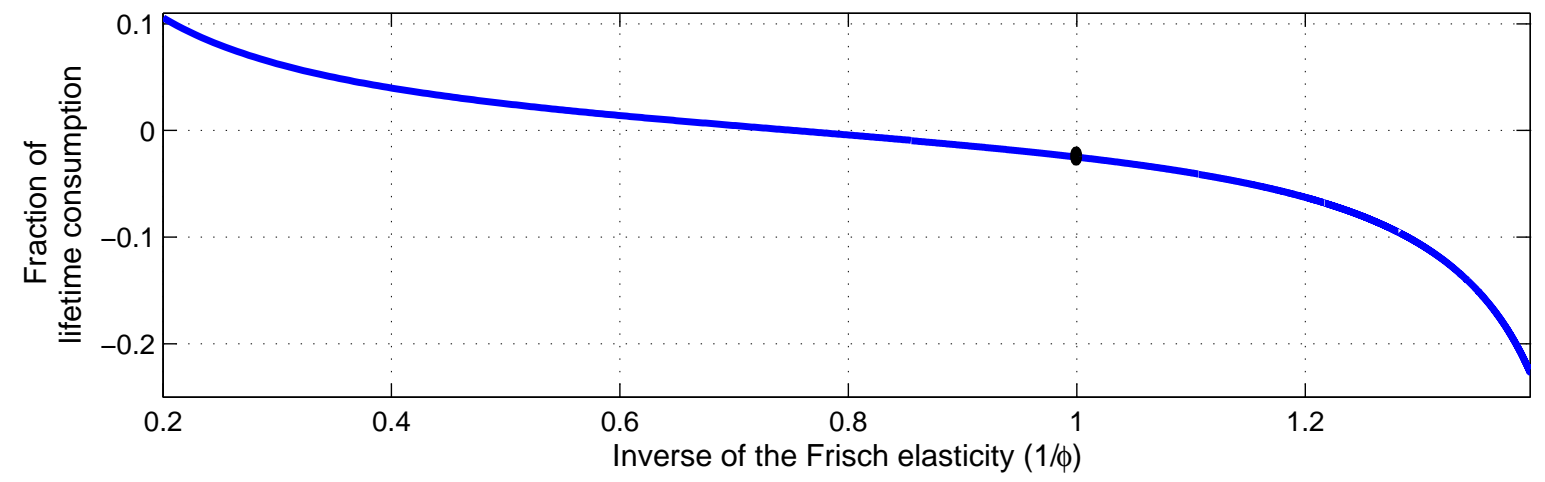

(B) Welfare change from completing markets $(\chi)$ and from eliminating risk $(\kappa)$

$$
\left(\mathrm{v}_{\alpha}=0.22, \mathrm{v}_{\varepsilon}=0.13\right)
$$

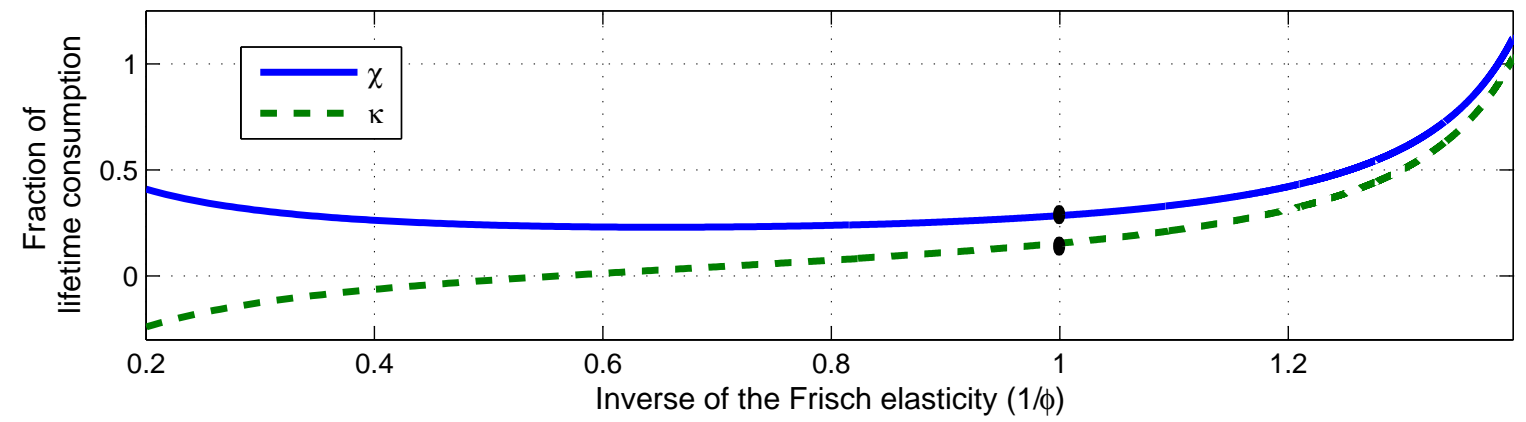

(C) Coefficient of Risk Aversion as a function of $1 / \phi$

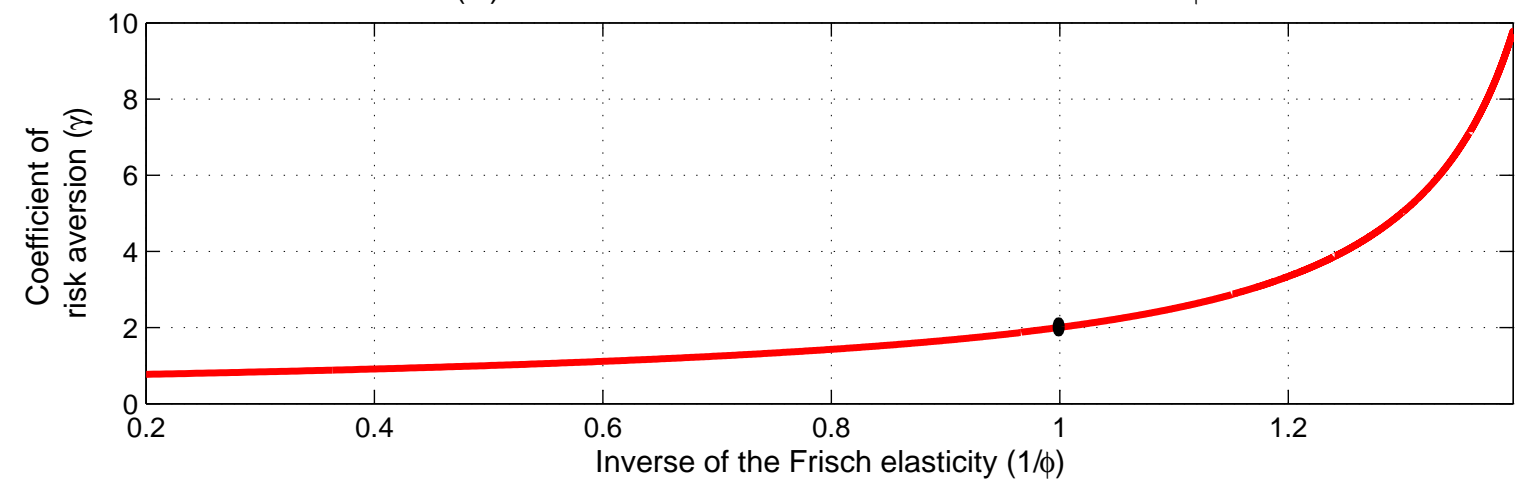

Figure 1: Cobb-Douglas Preferences: Panel (A) plots the welfare effect from a change in wage dispersion as a function of the inverse of the Frisch elasticity. Panel (B) plots the welfare effects from completing the markets and eliminating risk as a function of the inverse of the Frisch elasticity. Panel (C) plots the coefficient of risk aversion as a function of the inverse of the Frisch elasticity, assuming $\eta=1 / 3$. Panels $(\mathrm{A})$ and $(\mathrm{B})$ are based on the estimates for (changes in) $v_{\alpha}$ and $v_{\varepsilon}$ described in Section 7.1. The black dots represent the baseline parameterization. 
(A) Welfare effect from rising labor market risk $(\omega)$

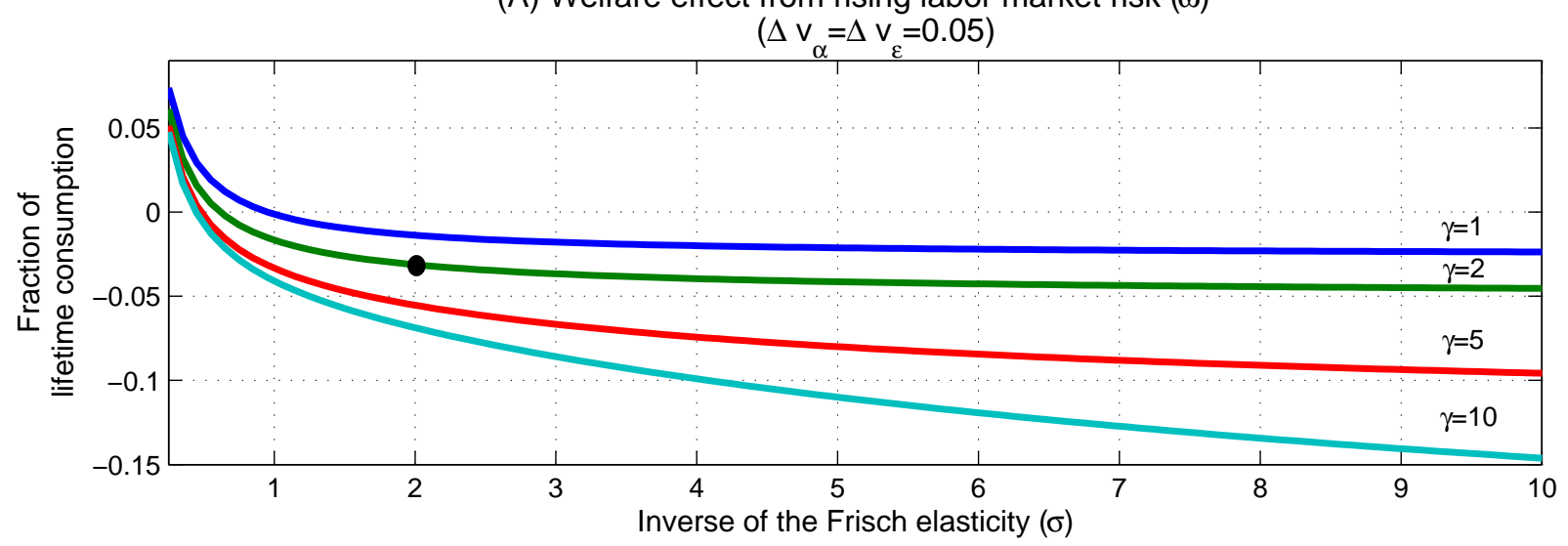

(B) Welfare change from completing markets $(\chi)$

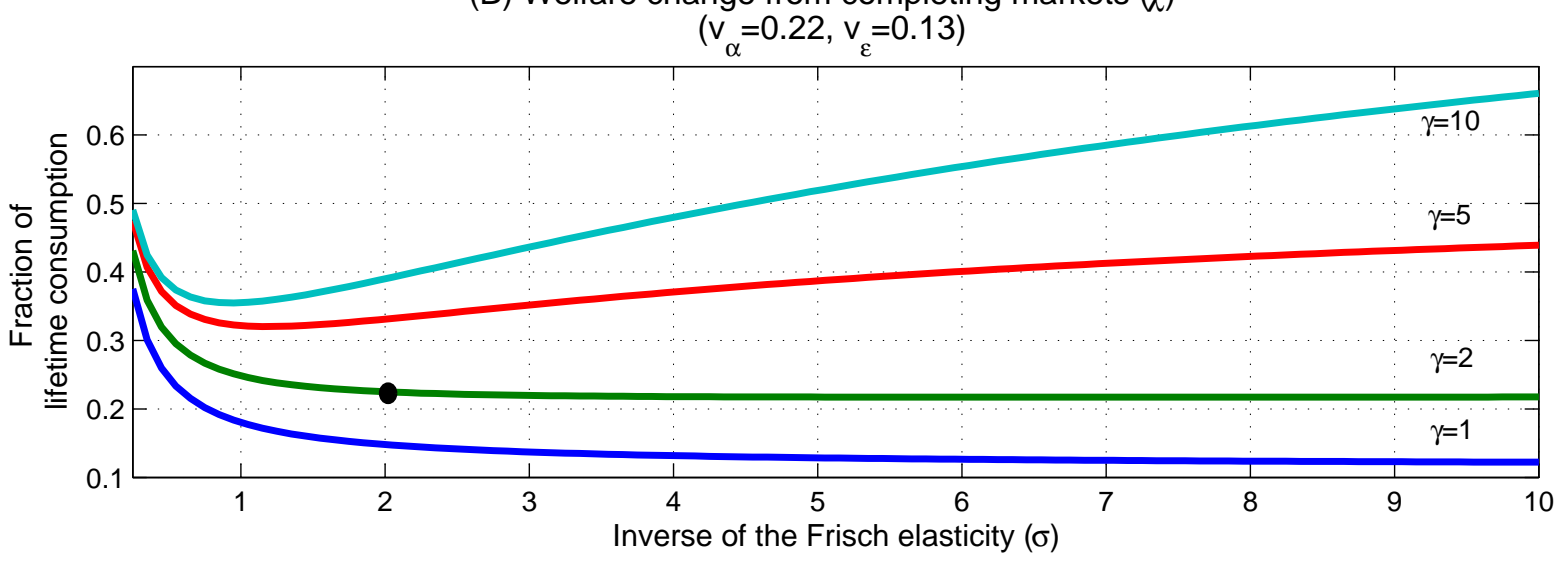

(C) Welfare change from eliminating risk $(\kappa)$

$\left(\mathrm{v}_{\alpha}=0.22, \mathrm{v}_{\varepsilon}=0.13\right)$

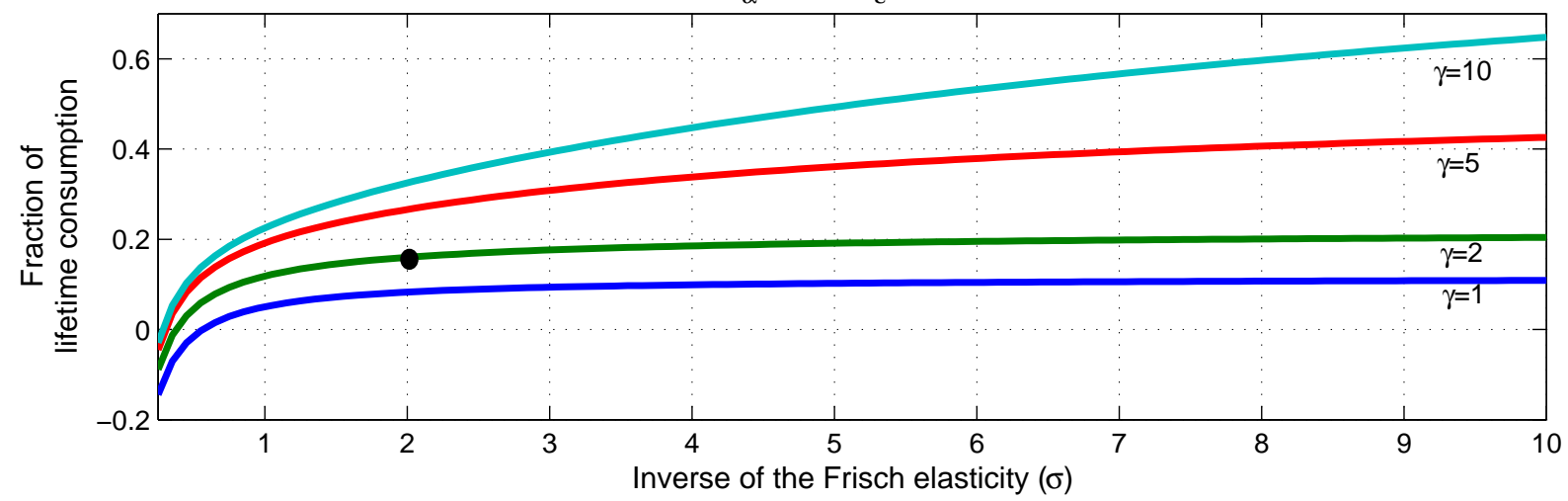

Figure 2: Separable Preferences: Panel (A) plots the welfare effect from a change in wage dispersion as a function of the inverse of the Frisch elasticity. Panel (B) plots the welfare gain from completing markets as a function of the inverse of the Frisch elasticity. Panel (C) plots the welfare change from eliminating risk as a function of the inverse of the Frisch elasticity. All plots are based on the estimates for (changes in) $v_{\alpha}$ and $v_{\varepsilon}$ described in Section 7.1. The black dots represent the baseline parameterization. 